\title{
Multidisciplinary Engineering for the Utilization of Traditional Automated Storage and Retrieval System (ASRS) for Firefighting in Warehouses
}

\author{
Ahmed Farouk AbdelGawad \\ Mech. Eng. Dept., Umm Al-Qura Univ., Makkah, Saudi Arabia \\ Email address: \\ afaroukg@yahoo.com \\ To cite this article: \\ Ahmed Farouk AbdelGawad. Multidisciplinary Engineering for the Utilization of Traditional Automated Storage and Retrieval \\ System (ASRS) for Firefighting in Warehouses. American Journal of Energy Engineering. Special Issue: Fire, Energy and Thermal Real-life \\ Challenges. Vol. 3, No. 4-1, 2015, pp. 1-22. doi: 10.11648/j.ajee.s.2015030401.11
}

\begin{abstract}
A S R S$ is usually installed in a factory or warehouse to increase storage capacity, floor space utilization, labor productivity in storage operations and stock rotations etc. ASRS systems are custom-planned for each individual application, and they range in complexity from relatively small mechanized systems that are controlled manually to very large computercontrolled systems that are fully integrated with factory and warehouse operations. The purpose of the present paper is to gain experience in multidiscipline engineering through the design, fabrication and implementation of ASRS model in a capstone (graduation) project. The scope of the project was extended by considering the fire fighting in $A S R S$ warehouses. In the present project, the students designed, manufactured and implemented an ASRS model. The model was automatically controlled by a microcontroller-based electronic circuit. The students succeeded in designing, building and testing their model. Based on their practical experience, they proposed a new technique for firefighting in $A S R S$ warehouses.
\end{abstract}

Keywords: Multidisciplinary Engineering, $A S R S$, Warehouse, Firefighting

\section{Introduction}

\subsection{Multidisciplinary Engineering}

As new skills are required of engineering graduates to respond to ever-changing societal needs, research on engineering learning systems is required to effectively adapt and respond to those needs. Multidisciplinary, team-taught, project-based instruction has shown effectiveness in teaching teamwork, communication, and life-long learning skills, and appreciation for other disciplines. Unfortunately, this instruction mode has not been widely adopted, largely due to its resource-intensiveness [1].

Another important objective is the development of professional skills of students. Developing professional skills to improve students' awareness of the engineering practice enhances the overall competence of students and provides lifelong learning skills including proficiency in communication, engineering ethics, professional presentations, professional etiquette, and project management [2].

The multidisciplinary approach was considered by many researchers [3-10] for both under- and post-graduate engineering studies.

The present paper covers an engineering graduation project as an adaptation of the multidisciplinary learning technique. The students developed a model of an automated storage and retrieval system (ASRS). The multidisciplinary topics cover problem-definition and analysis, mechanical design, material selection, manufacturing, selection of electrical motors, and design, programming and implementation of electronic control circuits and sensors. Also, multidisciplinary engineering may be extended to firefighting in $A S R S$ warehouses in emergency situations.

\subsection{What is ASRS}

An automated storage and retrieval system ( $A S R S$ or $A S / R S)$ consists of a variety of computer-controlled systems for automatically placing and retrieving loads from defined storage locations. Automated storage and retrieval systems $(A S R S)$ are typically used in applications where: $(i)$ There is a very high volume of loads being moved into and out of storage. (ii) Storage density is important because of space constraints; no value adding content is present in this process. 
(iii) Accuracy is critical because of potential expensive damages to the load. ASRS can be used with standard loads as well as nonstandard loads [11]. Automated storage and retrieval systems have been widely used in distribution and production environments since their introduction in the 1950s [12]. More details about ASRS can be found in Refs. [13-21]. Figure 1 shows some examples of real-life $S A R S$.

The utilization of $A S R S$ has many benefits that may be listed as: (i) Improving storage capacity and operator efficiency, (ii) Increasing accuracy of stock handling, (iii) Maximizing the benefits of available storage space, (iv) Reducing labor costs, ( $v$ ) Reducing stock damage and waste costs, (vi) Improving customer service, (vii) Real-time inventory control, (viii) Preventing personnel from harsh working conditions, e.g., working in cold food-storage utilities.

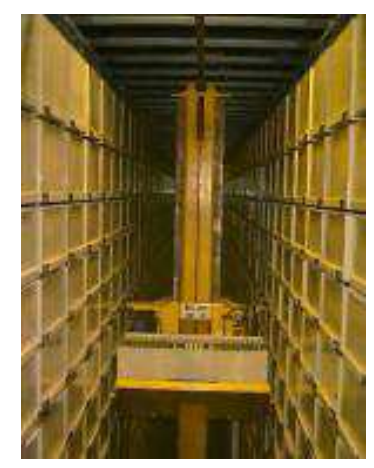

(a) $[22]$

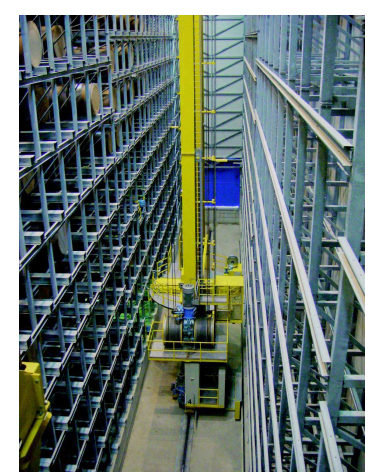

(b) [23]

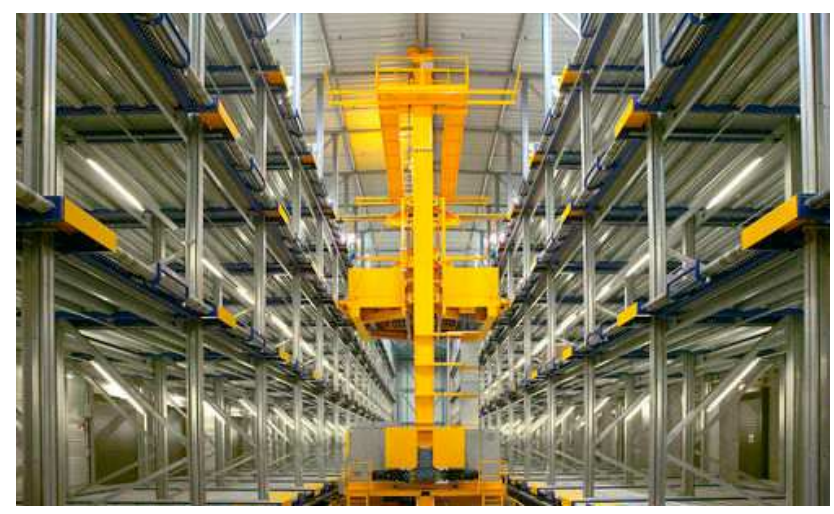

(c) [24]

Figure 1. Some examples of real-life SARS.

\subsection{Problems of Conventional Storage Systems}

The performance of any manufacturing industry depends mostly on its material handling and storage system [25]. Thus, the conventional storage systems have many practical problems that can be listed as: (i) Lost or damage of stored products, (ii) Difficulties of inventory access, (iii) Much time is usually spent for stock searching, (iv) Delaying the customer's delivery as orders spend much time in the factory, (v) Inaccurate inventory records, (vi) Wasting of considerably much space, (vii) Workers may be exposed to dangerous situations, (viii) Excess quantities of inventory.

\subsection{Types of ASRS}

Several important categories of ASRS can be distinguished based on certain features and applications. The following are the principle types [26]:

\subsubsection{Unit-Load ASRS}

The unit load $A S R S$ is used to store and retrieve loads that are palletized or stored in standard-sized containers. The system is computer controlled. The $S R$ (storage and retrieval) machines are automated and designed to handle the unit load containers. Usually, a mechanical clamp mechanism on the $S R$ machine handles the load. However, there are other mechanisms such as a vacuum or a magnet-based mechanism for handling sheet metal. The loads are generally over $500 \mathrm{lb}$ per unit. The unit-load system is the generic ASRS.

\subsubsection{Mini-Load ASRS}

This system is designed to handle small loads such as individual parts, tools, and supplies that are contained in bins or drawers in the storage system. Such a system is applicable where the availability of space is limited. It also finds its use where the volume is too low for a full-scale unit load system and too high for a manual system. A mini-load $A S R S$ is generally smaller than a unit-load $A S R S$ and is often enclosed for security of items stored.

\subsubsection{Deep-Lane ASRS}

This is a high-density unit load storage system that is appropriate for storing large quantities of stock. The items are stored in multi deep storage with up to 10 items in a single rack, one load behind the next. Each rack is designed for flow-through, with input and output on the opposite side. Machine is used on the entry side of the rack for input load and loads are retrieved from other side by an $S R$-type machine. The $S R$ machines are similar to unit-load $S R$ machine except that it has specialized functions such as controlling rack-entry vehicles.

\subsubsection{Man-on-Board ASRS}

This system allows storage of items in less than unit-load quantities. Human operator rides on the carriage of the $S R$ machine to pick up individual items from a bin or drawer. The system permits individual items to be picked directly at their storage locations. This provides an opportunity to increase system throughput. The operator can select the items 
and place them in a module. It is then carried by the $S R$ machine to the end of the aisle or to a conveyor to reach its destination.

\subsubsection{Automated Item Retrieval System}

This system is designed for retrieval of individual items or small product cartoons. The items are stored in lanes rather than bins or drawers. When an item is retrieved from the front by use of a rear-mounted pusher bar, it is delivered to the pickup station by pushing it from its lane and dropping onto a conveyor. The supply of items in each lane is periodically replenished and thus permitting first-in/first-out inventory rotation. After moving itself to the correct lane, the picking head activates the pusher mechanism to release the required number of units from storage.

\section{Present ASRS Model}

\subsection{Objectives}

The main objectives of the present project can be summarized as:

(i) Design a model, with a suitable size, of automated storage and retrieval system (ASRS) for small loads.

(ii) Fabrication, assembling, and testing the model.

(iii) Integrating simple control system (microcontrollerbased) on the storage/retrieval (SR) machine.

(iv) Proposing a new firefighting technique for small-load units.

(v) Covering the learning skills that are mentioned in Sec. 1.1.

\subsection{Project Scope}

The present project focuses on design and fabrication of the ASRS model. The design was mainly developed using "Autodesk Inventor Professional" software. Programmable autonomously storage/retrieve $(S R)$ machine was used in conjunction to store and retrieve the small-load units. Furthermore, students designed and implemented an electronic circuit to control the movement of the $S R$ machine. The movement of this system is limited to store and retrieve small-load units into and from storage structure (cupboards). Also, the students came up with a new technique for the firefighting of fire that may ignite in such small-load units. This technique is based on the practical experience of the present project.

\section{Design and Fabrication of the Present ASRS Model}

This section covers the details of design and fabrication of the present ASRS model. The different components of the $A S R S$ will be explained with design drawings and pictures. Figure 2 shows an overall picture of the ASRS model including movement mechanism and storage structure (cupboard). The overall dimensions of ASRS model can be stated as: length $1.35 m$ (x-axis), height $0.65 m$ ( $y$-axis), width $0.25 m$ (z-axis).

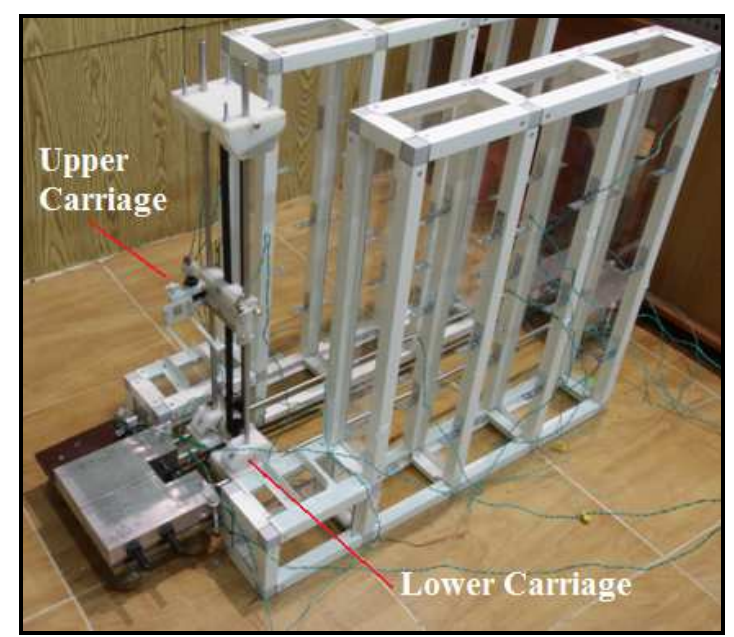

(a) An overall picture.

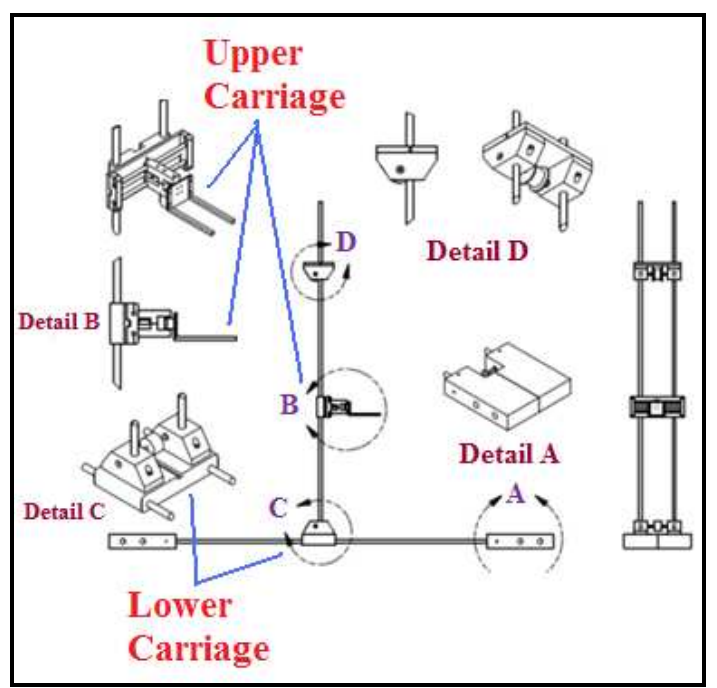

(b) Mechanical drawing.

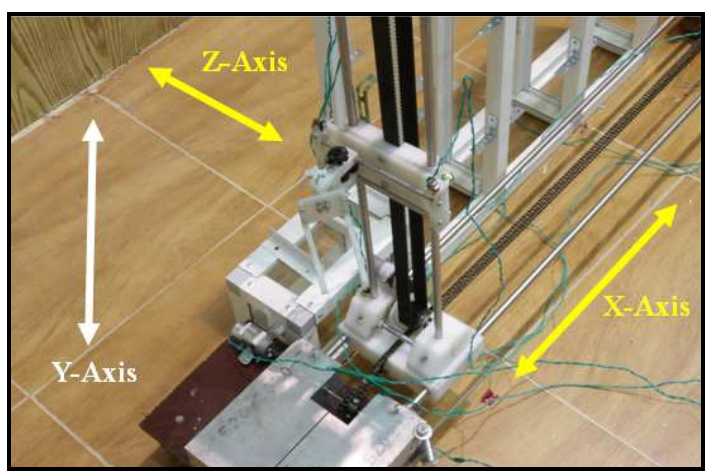

(c) Main axes of motion.

Figure 2. Present ASRS model.

Some parts of the ASRS model were fabricated in suitable workshops. Table 1 shows the details of these parts (components) including material selection, manufacturing technique, and quantity. Other parts (components) of the $A S R S$ model are ready-made that can be bought directly from the market. Table 2 shows the details of these ready-made parts. 
Table 1. Details of fabricated parts (components) in workshops.

\begin{tabular}{lllll}
\hline No. & $\begin{array}{l}\text { Part } \\
\text { (Component) }\end{array}$ & $\begin{array}{l}\text { Material } \\
\text { Selection }\end{array}$ & $\begin{array}{l}\text { Manufacturing } \\
\text { Technique }\end{array}$ & Quantity \\
\hline 1 & Rigid Base & Aluminium & & 4 \\
2 & Moving Base & PTFE & & 1 \\
3 & Guide Base & PTFE & & 4 \\
4 & Vertical Slider & PTFE & & 1 \\
5 & Guide Head & PTFE & Water Jet & $\&$ \\
& Plate & Traditional & 1 \\
6 & Holder Plate & PTFE & Machining & 1 \\
7 & Holder Arm & PTFE & & 2 \\
8 & Fork plate & PTFE & & 1 \\
9 & Fork arm & PTFE & & 1 \\
10 & Back holder & PTFE & & 2 \\
11 & H-Holder & PTFE & Sawing & 6 \\
12 & Guide rods & Stainless & & 1 \\
13 & Pulley & Pteel & Turning & 1 \\
\hline 14 & Timing pulley & PTFE & & \\
\hline
\end{tabular}

Table 2. Details of ready-made parts (components).

\begin{tabular}{llll}
\hline No. & Part (Component) & Type & Quantity \\
\hline 1 & Chain & Roller & 1 \\
2 & Belt & Timing flat & 1 \\
3 & Gears & Spur & 6 \\
& & Chain gears & 2 \\
4 & Bearings & Ball bearings & 8 \\
5 & coupling & Rigid coupling & 1 \\
6 & Springs & Compression \& & 1 \\
7 & Bolts & extension & As needed \\
8 & Nuts & Tap bolts & As needed \\
\hline
\end{tabular}

\subsection{Details of Fabricated Parts}

This section gives details of the parts (components) that were fabricated specifically for the present project in workshops. These parts are listed in Table 1.

\subsubsection{Rigid Base}

The rigid base is the base that carries the whole mechanism of ASRS. The rigid base, Fig. 3, is consisted of four symmetrical parts that are made of aluminum, Table 1 . These four parts constitute two main side bases; one on each side of the mechanism. The rigid base holds the two guide rods (10 $\mathrm{mm}$-diameter) that guide motion in $x$-axis. Figure 3 shows the mechanical drawings (Isometric, Elevation, Plan, Side view) of one of the four parts of the rigid base.

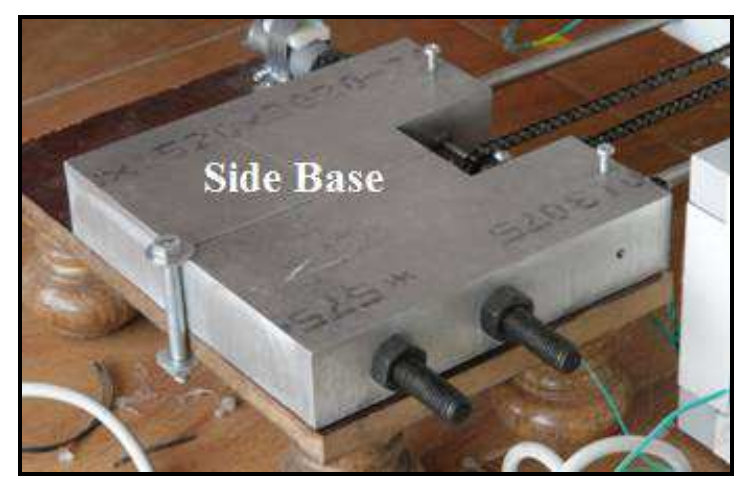

Figure 3. One of the two side bases of the rigid base of ASRS model.

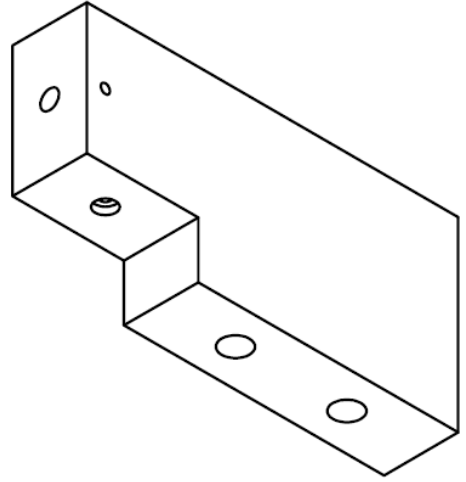

(a) Isometric

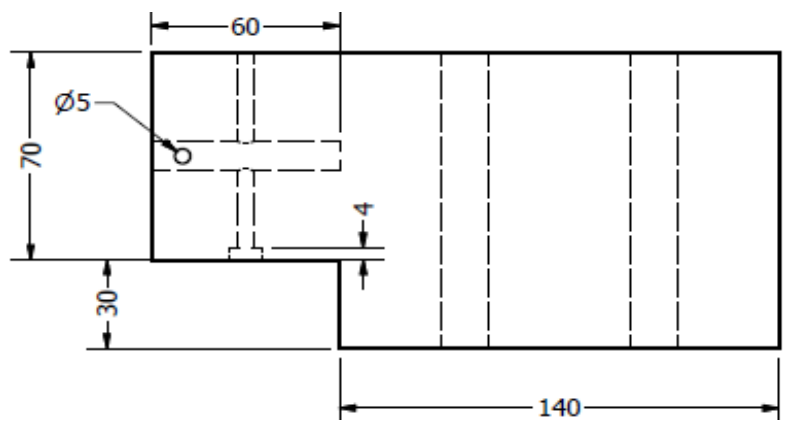

(b) Elevation

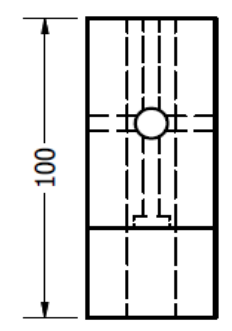

(c) Side view

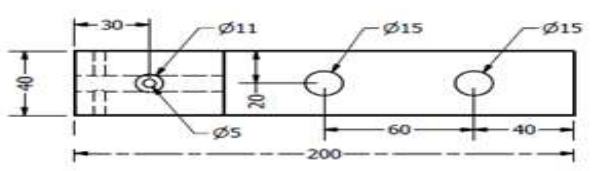

(d) Plan

Figure 4. Mechanical drawings of one of the four parts of the rigid base.

\subsubsection{Moving Base}

The moving base, which is made of PTFE, was designed to facilitate the movement of ASRS components in the horizontal direction, Fig. 5. It is moved in the either directions of $x$-axis (right or left) by a chain. The chain is driven be an electric motor. The chain is fixed to the moving base. The moving base is supported and guided by two metal rods. These two solid rods have a diameter of $10 \mathrm{~mm}$ and are made of stainless steel. Figure 6 shows the mechanical drawings (Isometric, Elevation, Plan, Side view) of the moving base. 


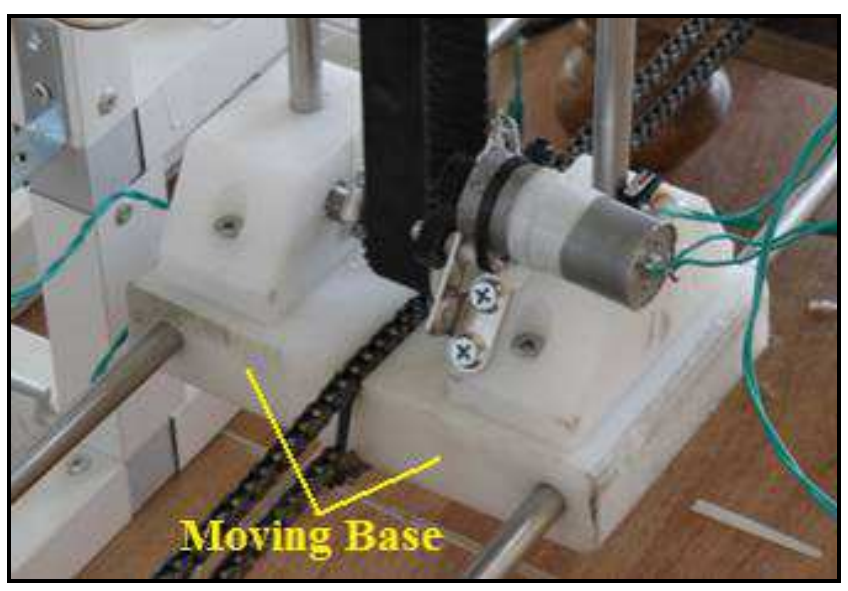

Figure 5. Moving base installed in ASRS model.

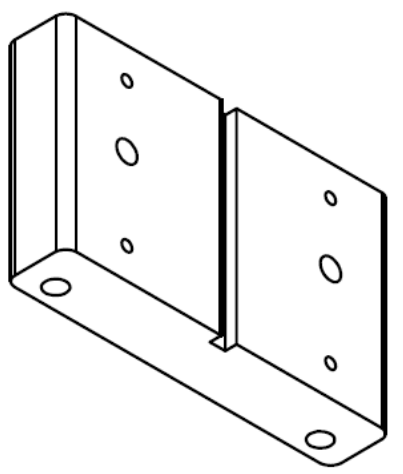

(a) Isometric

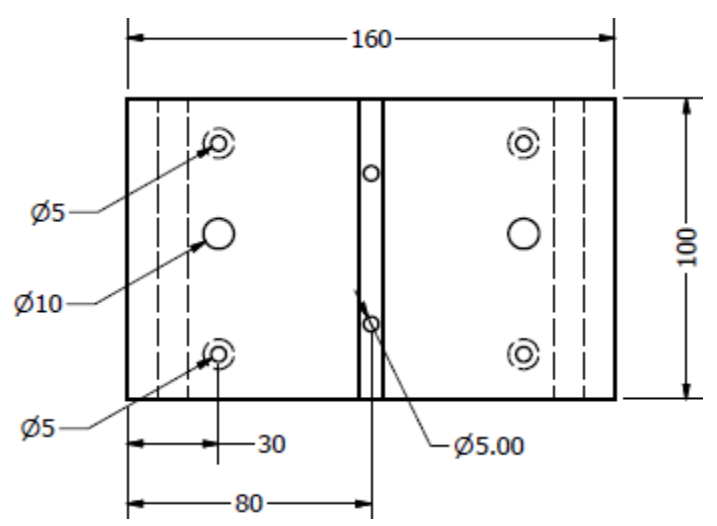

(b) Elevation

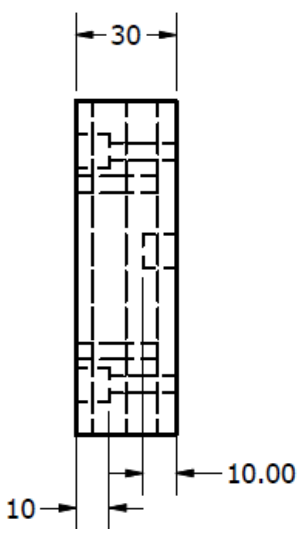

(c) Side view

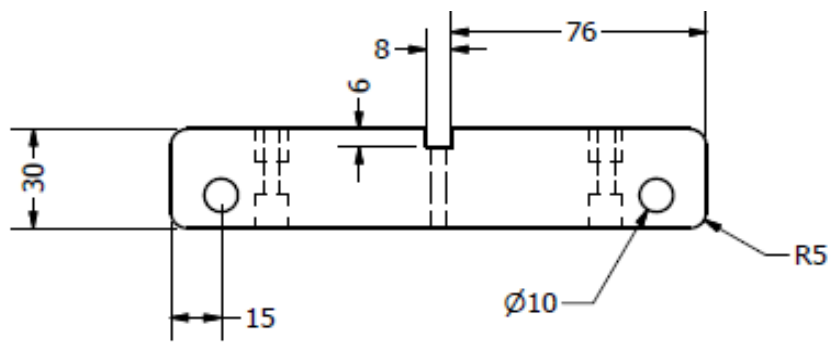

(d) Plan

Figure 6. Mechanical drawings of moving base.

\subsubsection{Guide Bases}

There are four guide bases that are designed to carry the vertical timing belt as well as the two guide rods (guides) in the vertical direction ( $y$-axis), Fig. 6. The guide bases are made of PTFE. Two of them are fixed on either side of the lower moving base, Fig. 4. The other two are fixed to an upper plate (Guide Head Plate), Fig. 7. The two vertical solid guide rods have a diameter of $10 \mathrm{~mm}$ and are made of stainless steel. The two vertical guide rods guide the motion along the $y$-axis. Figure 8 shows the mechanical drawings (Isometric, Elevation, Plan, Side view) of one of the guide bases.
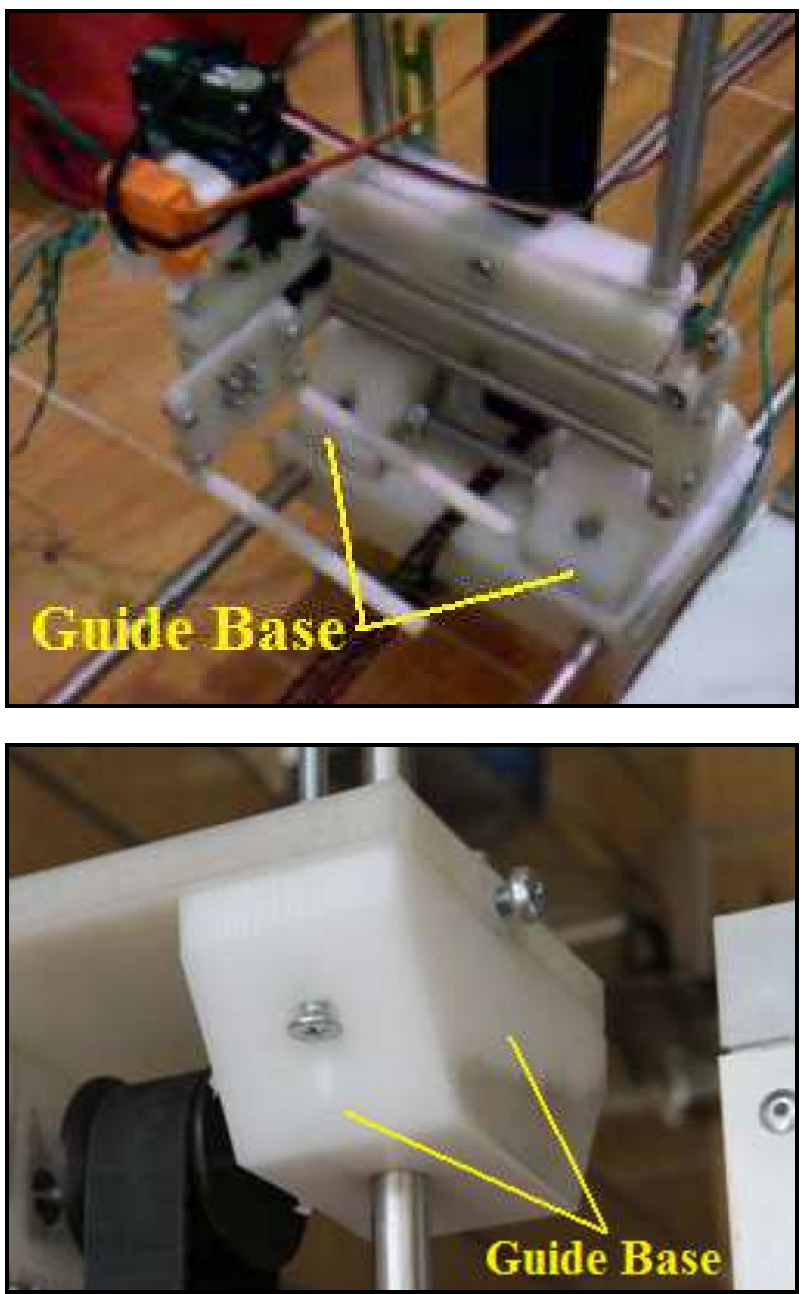

Figure 7. Guide base installed in ASRS model. 


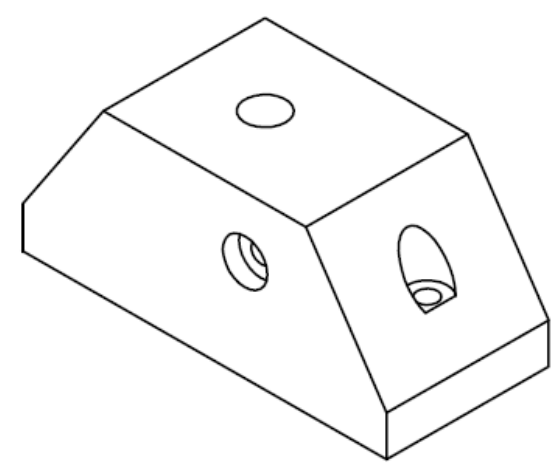

(a) Isometric

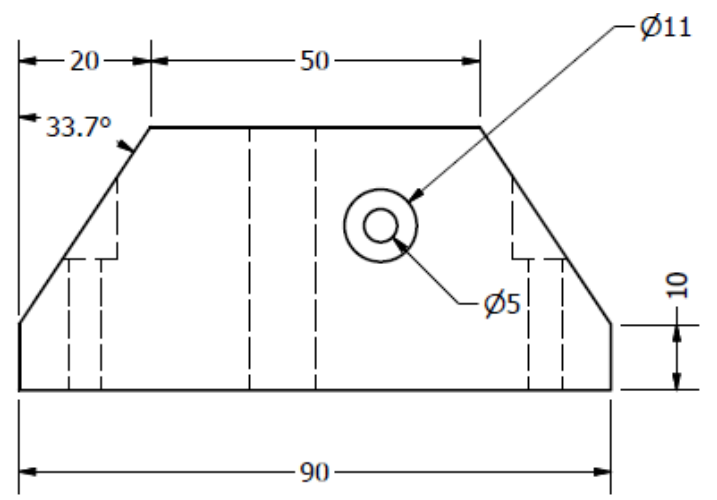

(b) Elevation

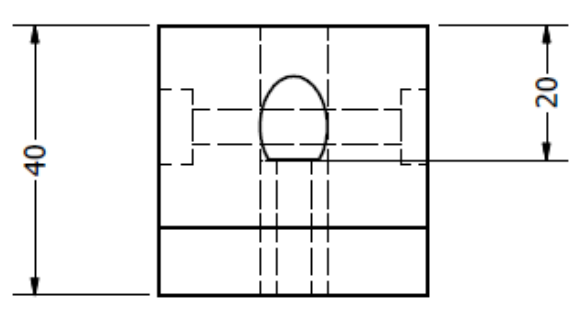

(c) Side view

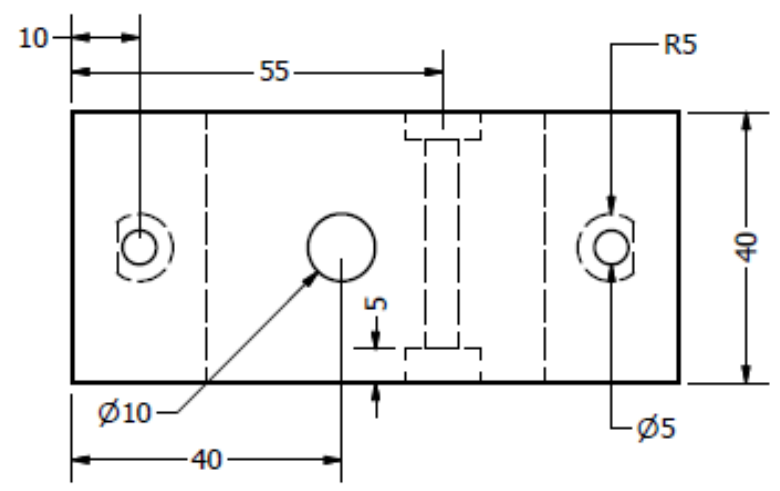

(d) Plan

Figure 8. Mechanical drawings of one of the guide bases.

\subsubsection{Vertical Slider}

The vertical slider is designed to carry the holder plate, Fig. 9. The vertical slider is made of PTFE. The vertical slider is fixed to the vertical belt by two bolts, Fig. 9. Thus, it moves strictly with the vertical belt. It slides on the two vertical solid guide rods. Figure 10 shows the mechanical drawings (Isometric, Elevation, Plan, Side view) of the vertical slider.

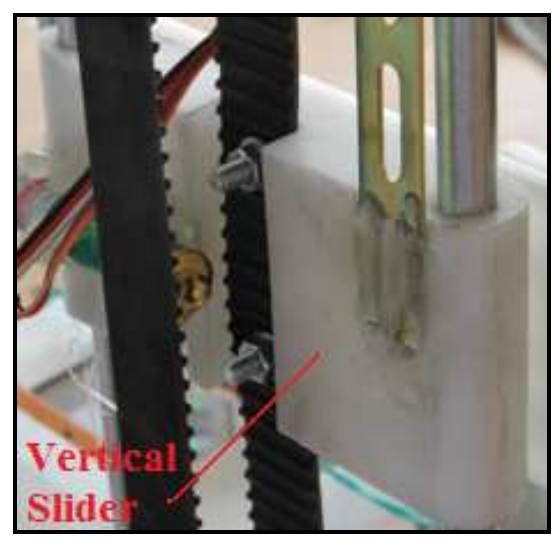

Figure 9. Vertical slider installed in ASRS model.

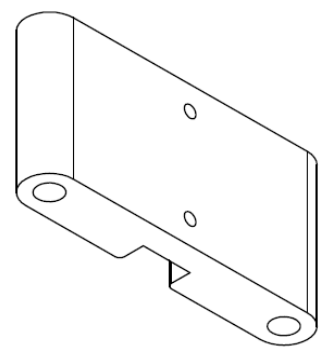

(a) Isometric

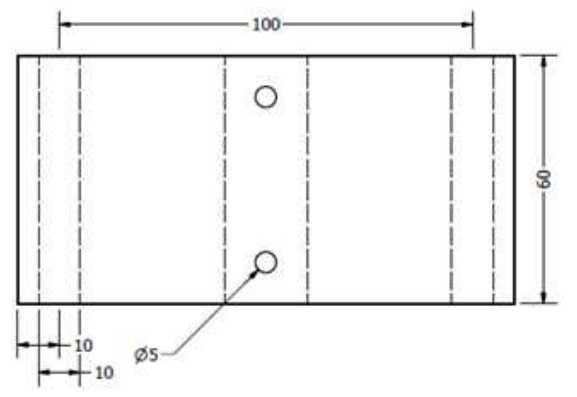

(b) Elevation

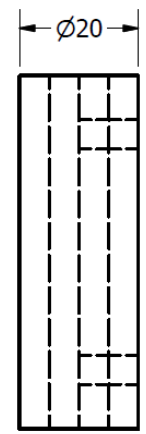

(c) Side view

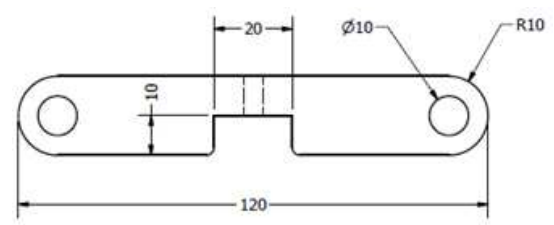

(d) Plan

Figure 10. Mechanical drawings of the vertical slider. 


\subsubsection{Guide Head Plate}

The guide head plate is an upper plate that is fixed to two of the guide bases, Fig. 11. It is made of PTFE. Also, it holds the two vertical solid guide rods into place. Figure 12 shows the mechanical drawings (Isometric, Elevation, Plan, Side view) of one of the guide head plate.

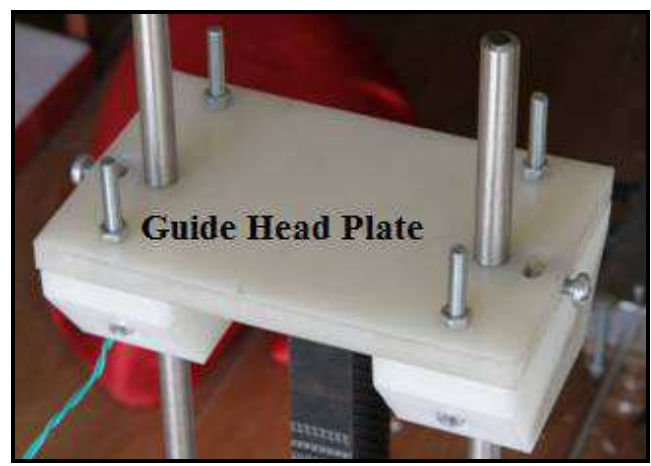

Figure 11. Guide head plate installed in ASRS model.

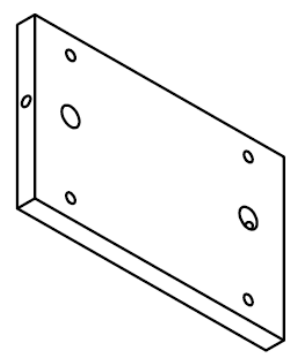

(a) Isometric

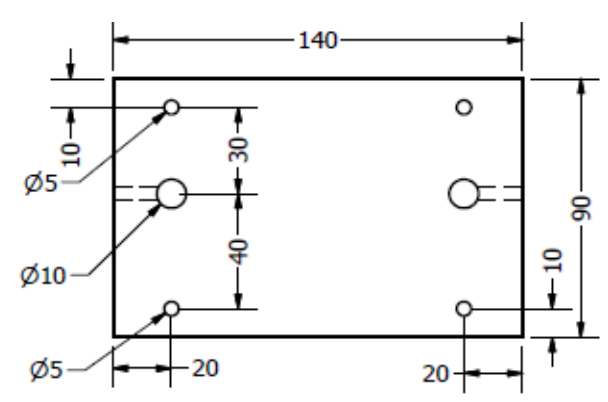

(b) Elevation

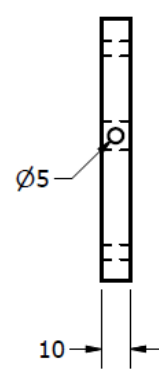

(c) Side view

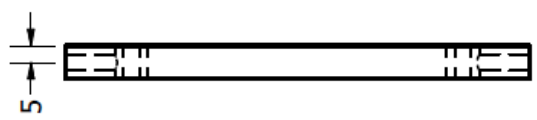

(d) Plan

Figure 12. Mechanical drawings of the guide head plate.

\subsubsection{Holder Plate}

The holder plate is fixed to the vertical slider by screws. It is designed to carry two horizontal solid guide rods that are used to guide the movement of the upper fork arms, Fig. 13. The holder plate is made of PTFE. The middle section of the holder plate is machined to present a toothed rack to enable the movement of the fork plate and fork arms in the $z$-axis. The holder plate is fixed to the belt that moves in the vertical direction ( $y$-axis) by two small bolts. Figure 14 shows the mechanical drawings (Isometric, Elevation, Side view) of the holder plate.

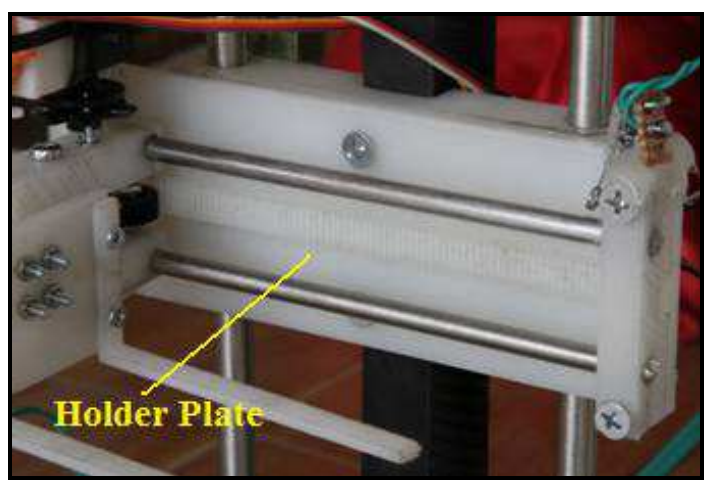

Figure 13. Holder plate installed in ASRS model.

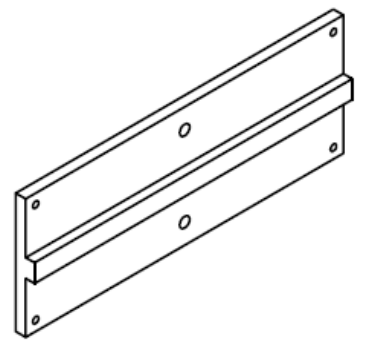

(a) Isometric

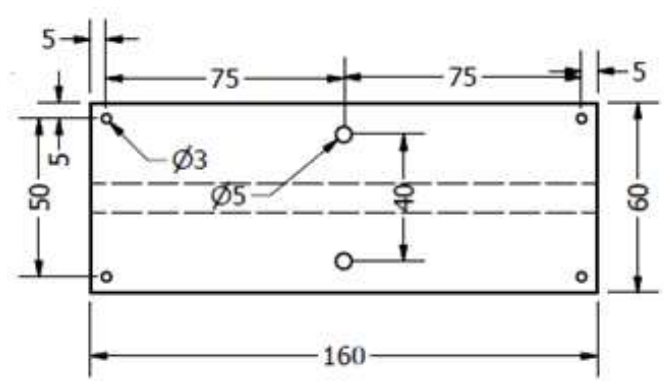

(b) Elevation

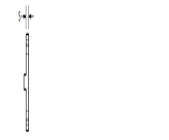

(c) Side view

Figure 14. Mechanical drawings of the holder plate. 


\subsubsection{Holder Arm}

Two holder arms are designed to fix the two upper horizontal solid guide rods $(5 \mathrm{~mm}$-diameter) that guide motion along $z$-axis, Fig. 15. Each holder arm is fixed to one of the two sides of the holder plate by a pair of screws. The two holder arms are made of PTFE. Figure 16 shows the mechanical drawings (Isometric, Elevation, Plan, Side view) of the holder arm.

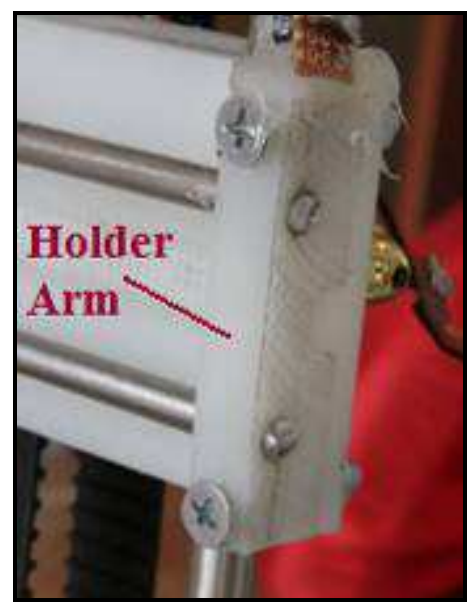

Figure 15. One of the two holder arms installed in ASRS model.

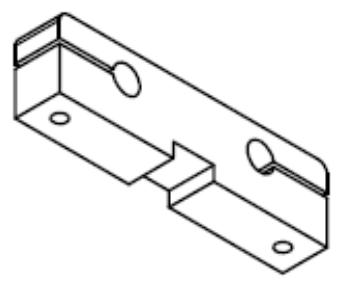

(a) Isometric

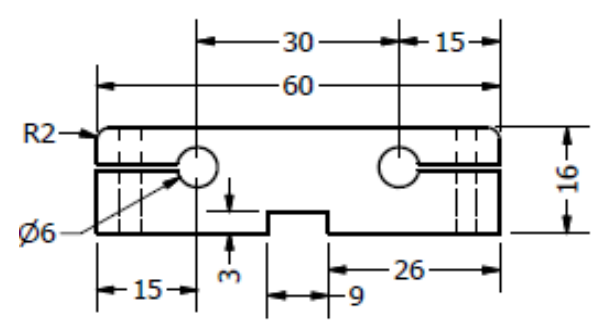

(b) Elevation

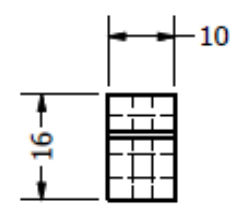

(c) Side view

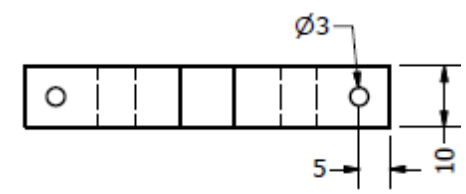

(d) Plan

Figure 16. Mechanical drawings of the holder arm.

\subsubsection{Fork Plate}

The fork plate is designed to carry the two fork arms, Fig. 17. The fork plate is made of PTFE. It is fixed into place by four bolts. Figure 18 shows the mechanical drawings (Isometric, Elevation, Side view) of the fork plate.

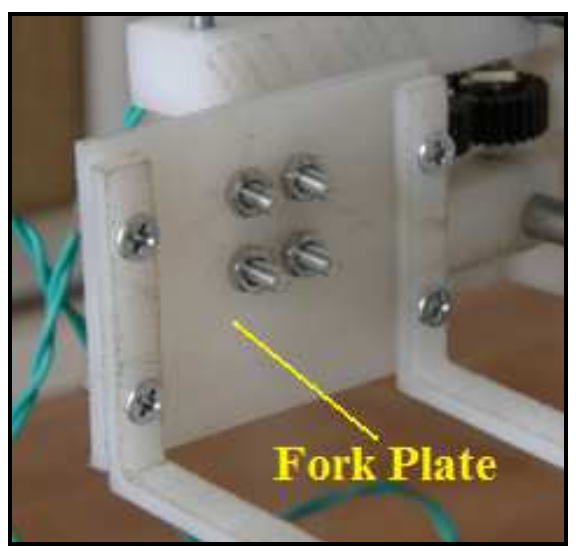

Figure 17. Fork plate installed in ASRS model.

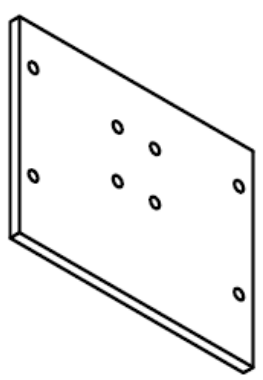

(a) Isometric

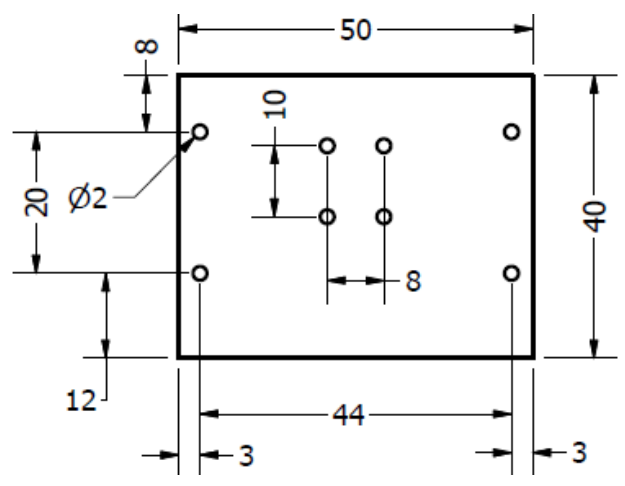

(b) Elevation

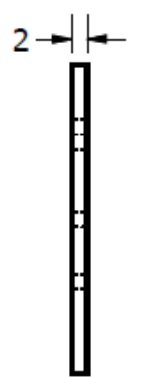

(c) Side view

Figure 18. Mechanical drawings of the fork plate. 


\subsubsection{Fork Arms}

The two fork arms are designed to carry the target stock (unit-load), Fig. 19. They are made of PTFE. They are fixed to fork plate by four screws. Figure 20 shows the mechanical drawings (Isometric, Elevation, Side view) of one of the fork arms.

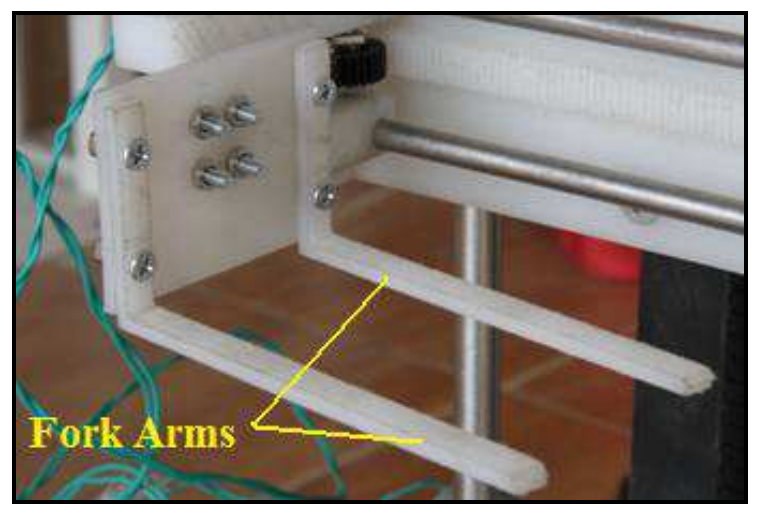

Figure 19. Fork arms installed in ASRS model.

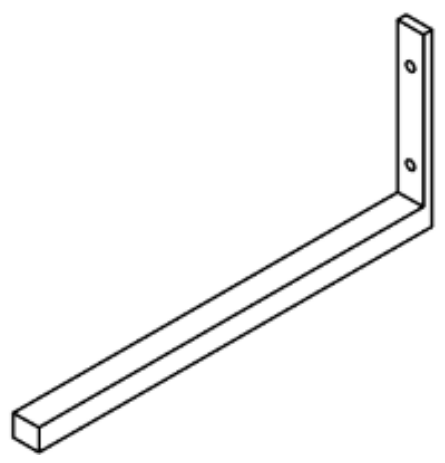

(a) Isometric

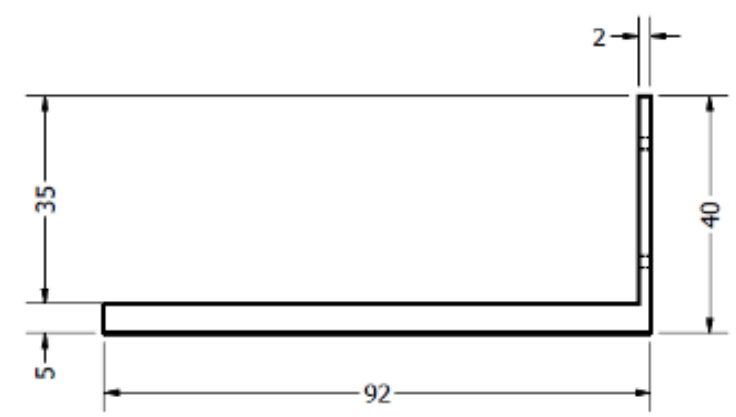

(b) Elevation

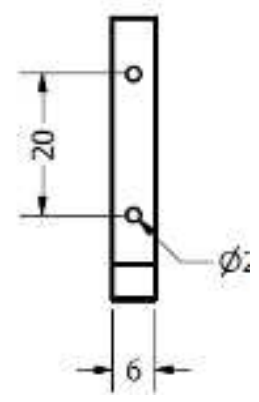

(c) Side view

Figure 20. Mechanical drawings of the fork arms.

\subsubsection{Back Holder}

The back holder was designed to fix the fork plate to the H-holder, Fig. 21. The back holder is made of PTFE. It is fixed into place by four bolts. Figure 22 shows the mechanical drawings (Isometric, Elevation, Plan, Side view) of the back holder.

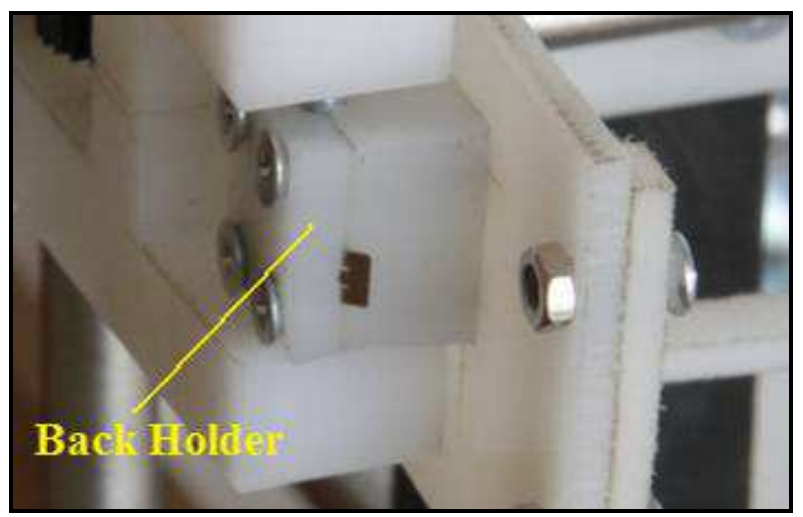

Figure 21. Back holder installed in ASRS model.

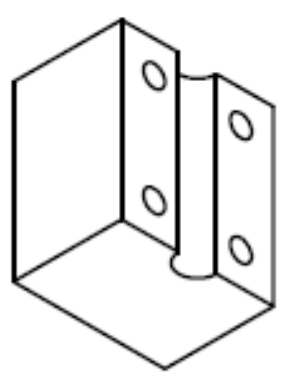

(a) Isometric

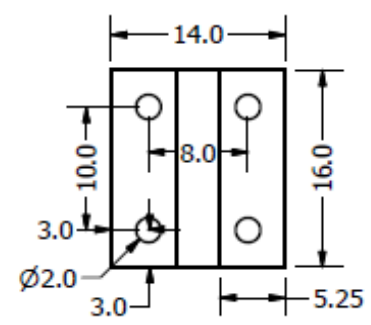

(b) Elevation

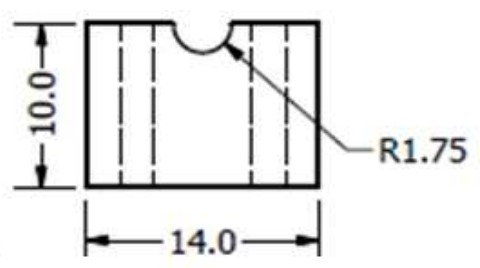

(c) Side view

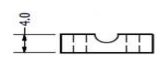

(d) Plan

Figure 22. Mechanical drawings of the back holder. 


\subsubsection{H-holder}

The H-holder was designed to carry the fork plate, fork arms, and transmission gears. It is consisted of two similar parts that have T-shape, Fig. 23. The two parts are made of $P T F E$. They are fixed to each other by a long bolt. Also, the two transmission gears are fixed in place to the H-holder by two bolts. Figure 24 shows the mechanical drawings (Isometric, Elevation, Plan, Side view) of one of the T-shape parts.

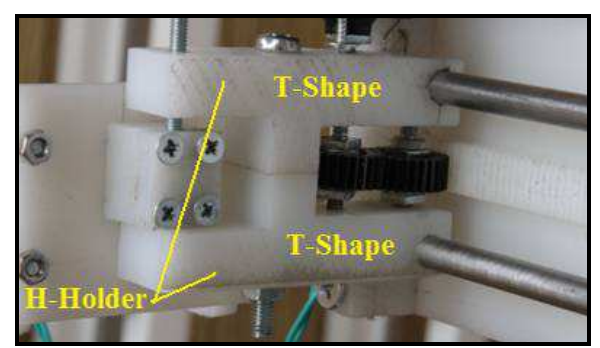

Figure 23. H-holder installed in ASRS model.

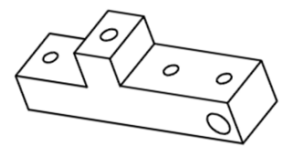

(a) Isometric

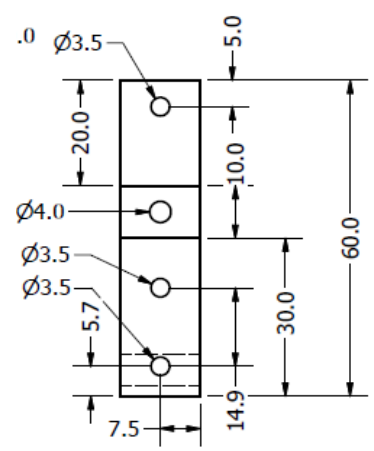

(b) Elevation

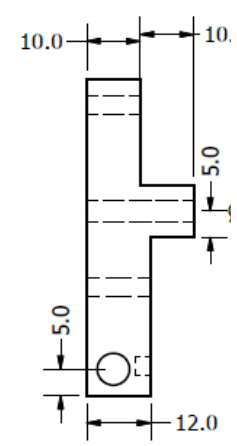

(c) Side view

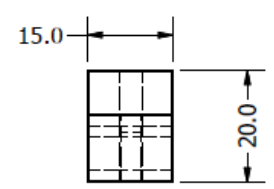

(d) Plan

Figure 24. Mechanical drawings of one of the T-shape parts.

\subsubsection{Solid Guide Rods}

There are six giude rods that guide the movement in the three main directions, Fig. 25. A pair of similar solid guide rods, which are made of stailess steel are used in every one of the three diections. The two rods have a diameter of $10 \mathrm{~mm}$ in both the $x$ - and $y$-dierction. Whereas, the two rods of the $z$-direction have a diameter of $5 \mathrm{~mm}$. The active lengthes of rods are $95,55,15 \mathrm{~cm}$ in $x$-, $y$-, and $z$-direction, respectively.

Figures 26-28 show two pictures for each of pair of rods along the three main directions; $x-, y$-, and $z$-axis, respectively.

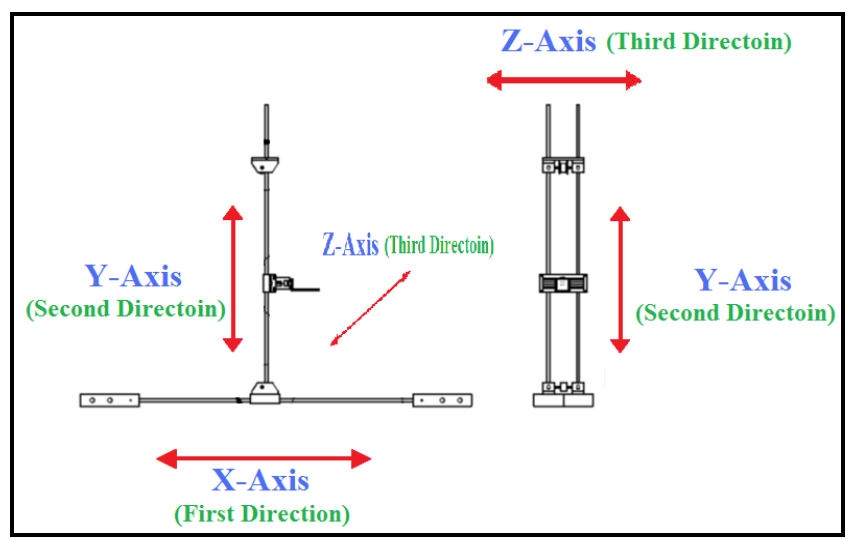

Figure 25. Three main axes (directions) of motion of the present ASRS model.

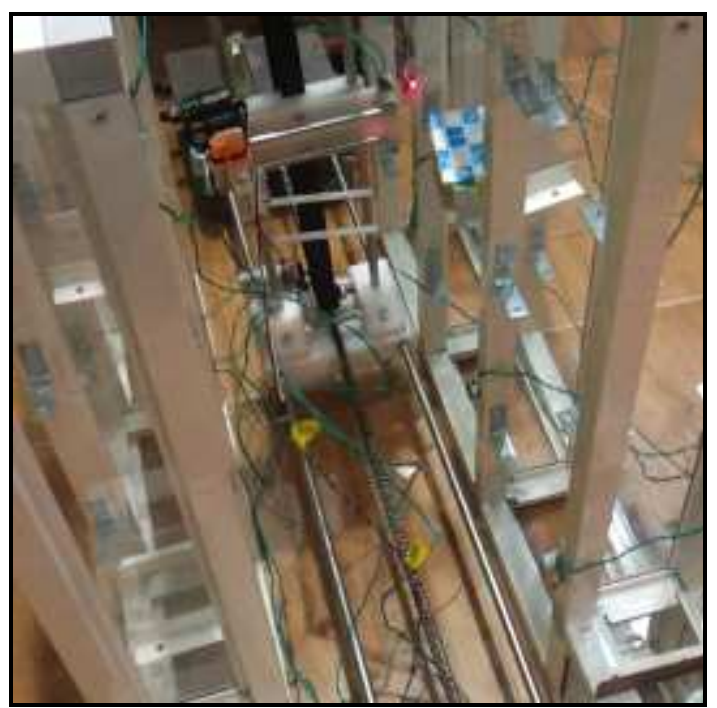

(a) Overall view

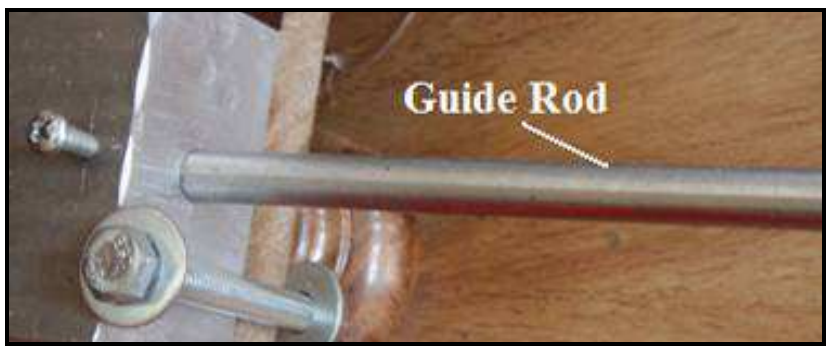

(b) Closer view.

Figure 26. The two guide rods along $x$-axis. 


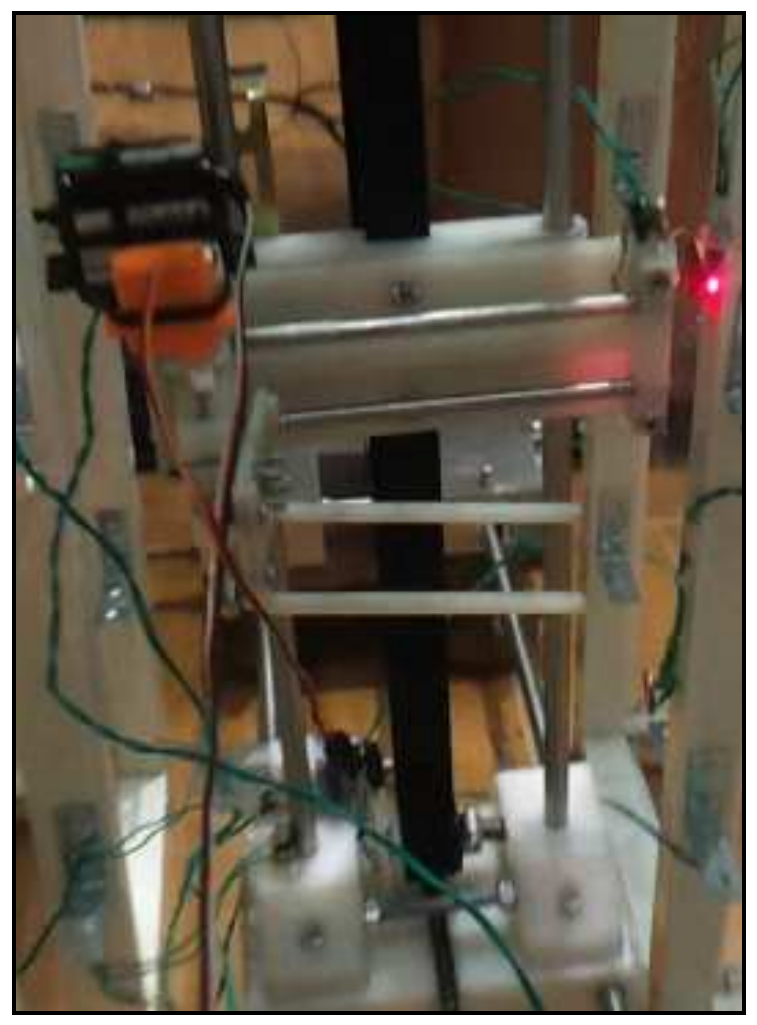

(a) Overall view.

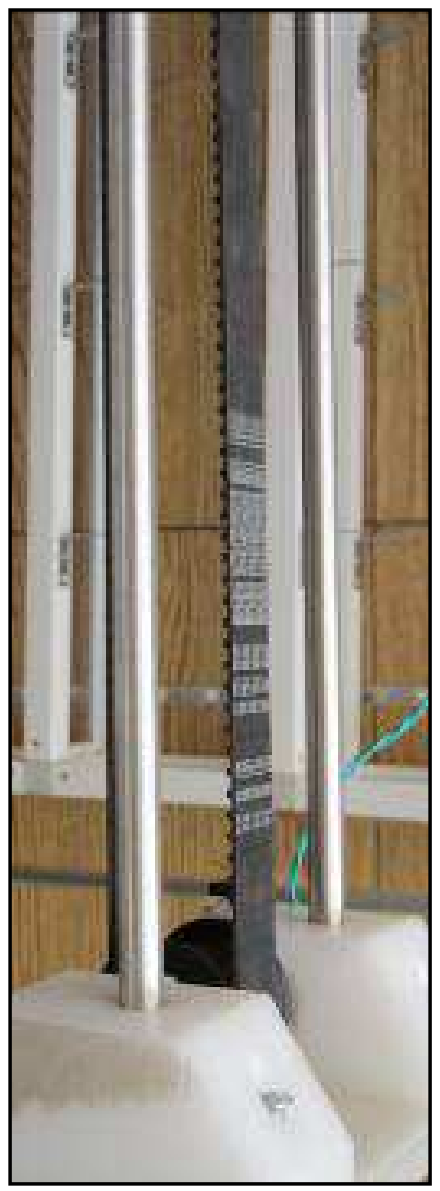

(b) Closer view.

Figure 27. The two guide rods along y-axis.

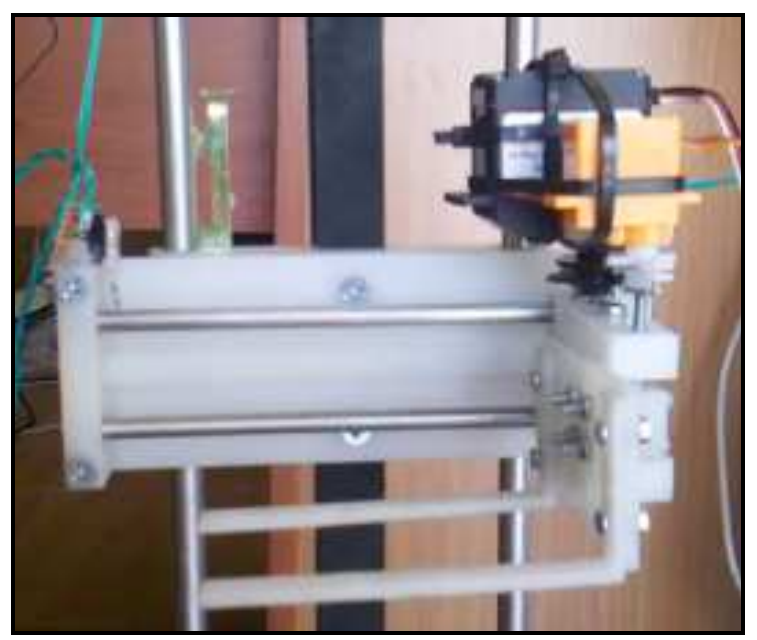

(a) Overall view.

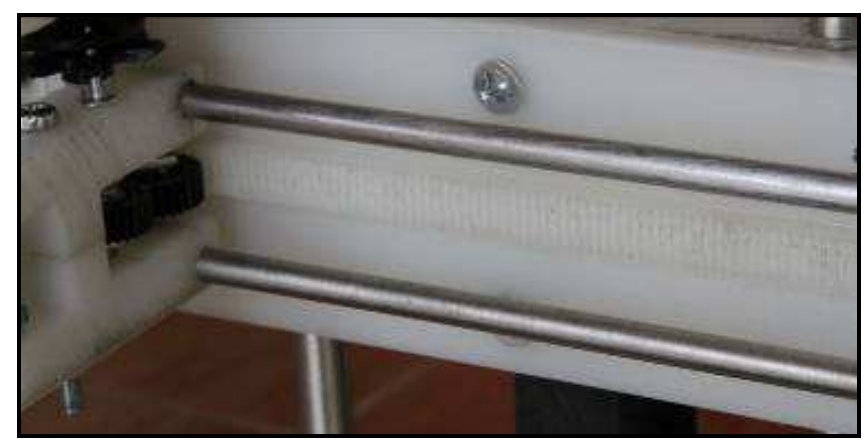

(b) Closer view.

Figure 28. The two guide rods along z-axis.

\subsubsection{Pulley}

A pulley was designed to carry the vertical belt that moves the holder plate (Sec. 3.1.6, Fig. 13). The pulley is made of PTFE, Fig. 29. The pulley is carried by a solid stainless steel rod that has a diameter of $4 \mathrm{~mm}$. The two ends of the rod are supported by two small bearings that have housing in the two upper guide bases (Sec. 3.1.3, Fig. 7). Figure 30 shows the mechanical drawings (Isometric, Elevation, Side view) of the pulley.

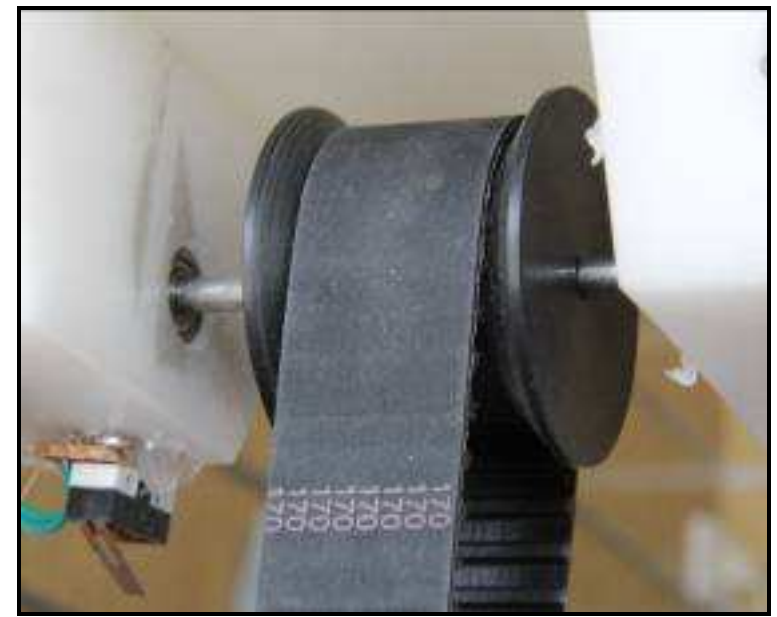

Figure 29. Pulley installed in ASRS model. 


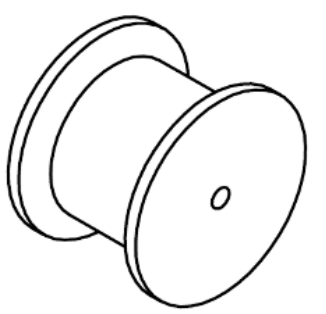

(a) Isometric

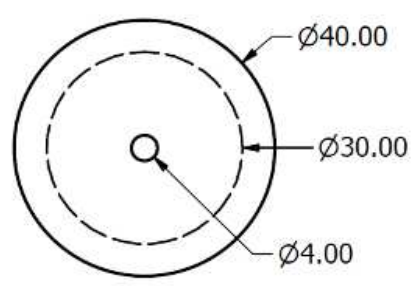

(b) Elevation

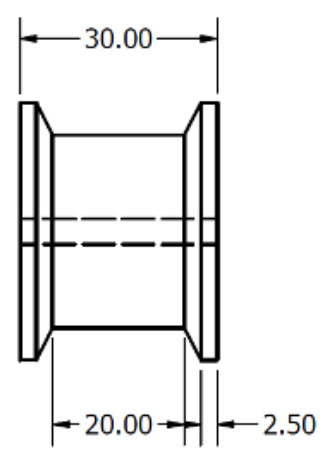

(c) Side view

Figure 30. Mechanical drawings of the pulley.

\subsubsection{Timing Pulley}

A timing pulley was designed to move the vertical belt that moves the holder plate (Sec. 3.1.6, Fig. 13). The pulley is made of PTFE, Fig. 31. The pulley is carried by a solid stainless steel rod that has a diameter of $4 \mathrm{~mm}$. The two ends of the rod are supported by two small bearings that have housing in the two lower guide bases (Sec. 3.1.3, Fig. 7). Figure 32 shows the mechanical drawings (Isometric, Elevation) of the timing pulley.

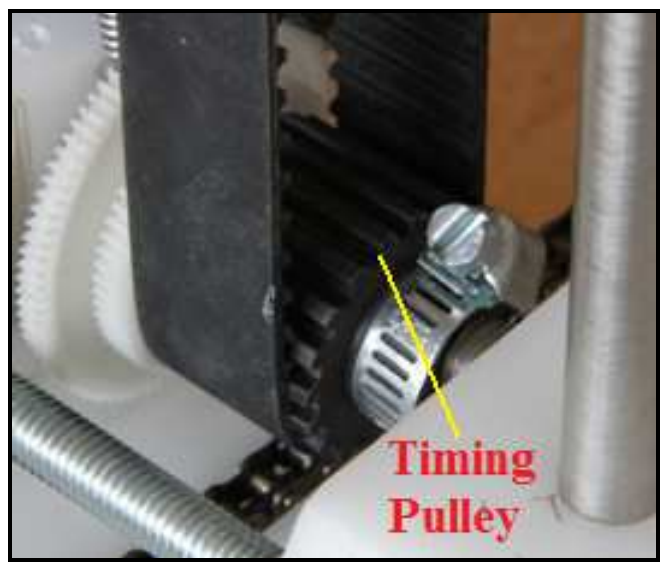

Figure 31. Timing pulley installed in ASRS model.

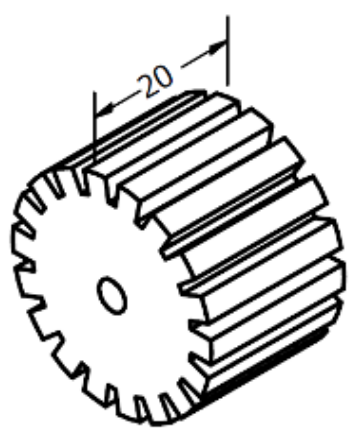

(a) Isometric

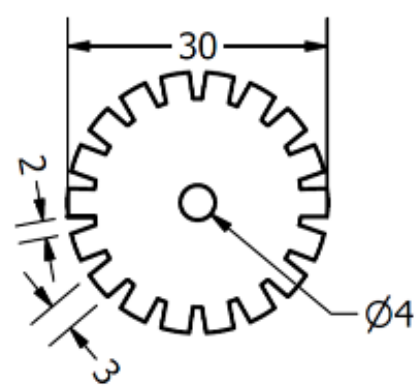

(b) Elevation

Figure 32. Mechanical drawings of the timing pulley.

\subsection{Details of Ready-Made Parts}

This section gives details of the ready-made parts (components) that were purchased directly from the market. These parts are listed in Table 2.

\subsubsection{Chain}

A suitable chain, Fig. 33, was used to move the moving base (Sec. 3.1.2, Fig. 5) that facilitates the movement of $A S R S$ components in the $x$-axis (first direction). The chain is connected to two chain gears that rest on the rigid base, Fig. 3. Each of the two chain gears is carried by a solid stainless steel rod that has a diameter of $4 \mathrm{~mm}$. The two ends of the rod are supported by two small bearings that have housing in the two sides of the rigid base. One of these chain gears, which is driven by a suitable electrical motor, is the driving gear of the chain.

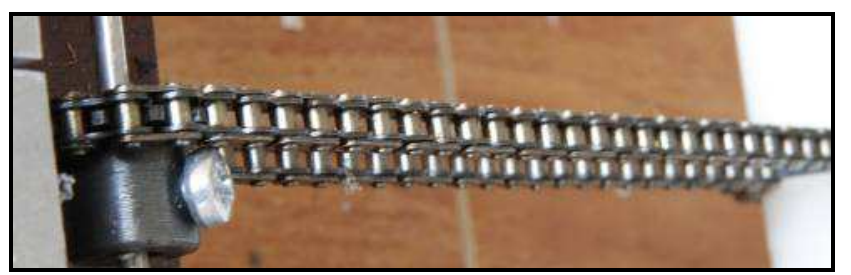

Figure 33. Chain (x-axis) installed in ASRS model.

\subsubsection{Timing Belt}

The timing belt, Fig. 34, is used to move the holder plate (Sec. 3.1.6, Fig. 13) vertically in the $y$-axis (second direction). The timing belt is driven by a timing pulley (Sec. 3.1.14, Fig. 31). A flat pulley (Sec. 3.1.13, Fig. 29) supports the other side of the timing belt. 


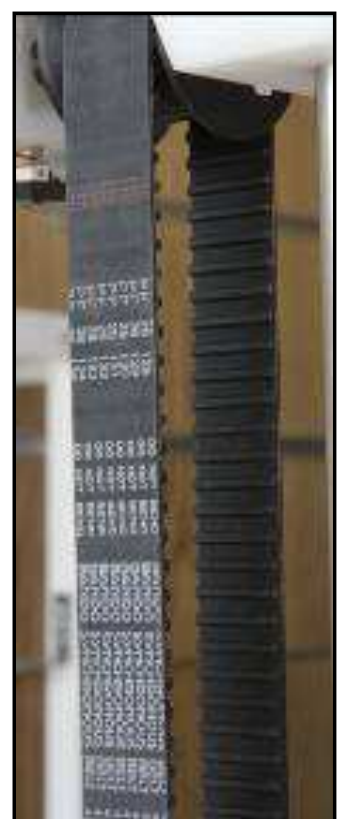

Figure 34. Timing belt (y-axis) installed in ASRS model.

\subsubsection{Gears}

A group of seven gears was used in the present project. Two of them are chain gears Fig. 35a. They were used to drive the chain (Sec. 3.2.1, Fig. 33). Five spur gears were also used, Fig. 35b. Two of the spur gears are housed in the H-holder (Sec. 3.1.11, Fig. 23). These two spur gears are used to move the fork plate (Sec. 3.1.8, Fig. 17) and fork arms (Sec. 3.1.9, Fig. 19). Three other spur gears, Fig. 35c, were used to move the timing belt (Sec. 3.2.2, Fig. 34) in the $y$-axis (second direction).

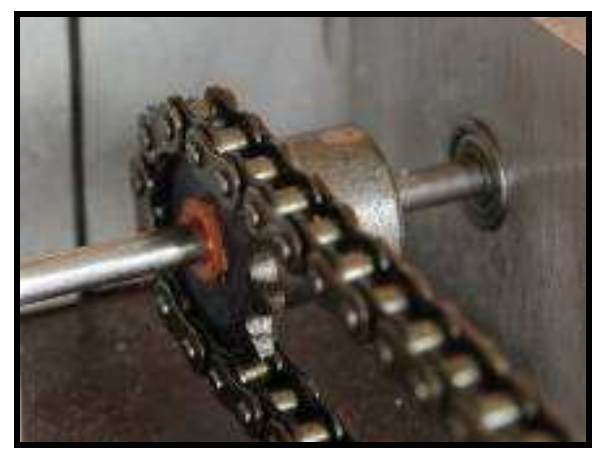

(a) Chain gear.

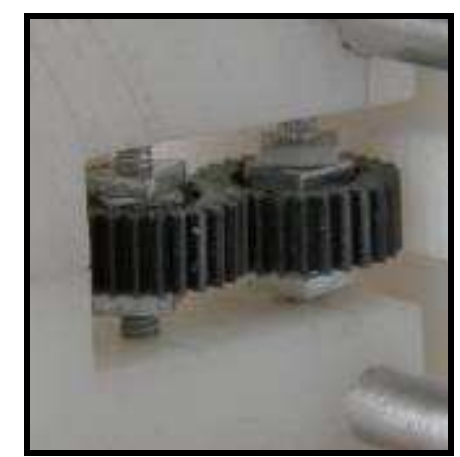

(b) Two supr gears of fork arms.

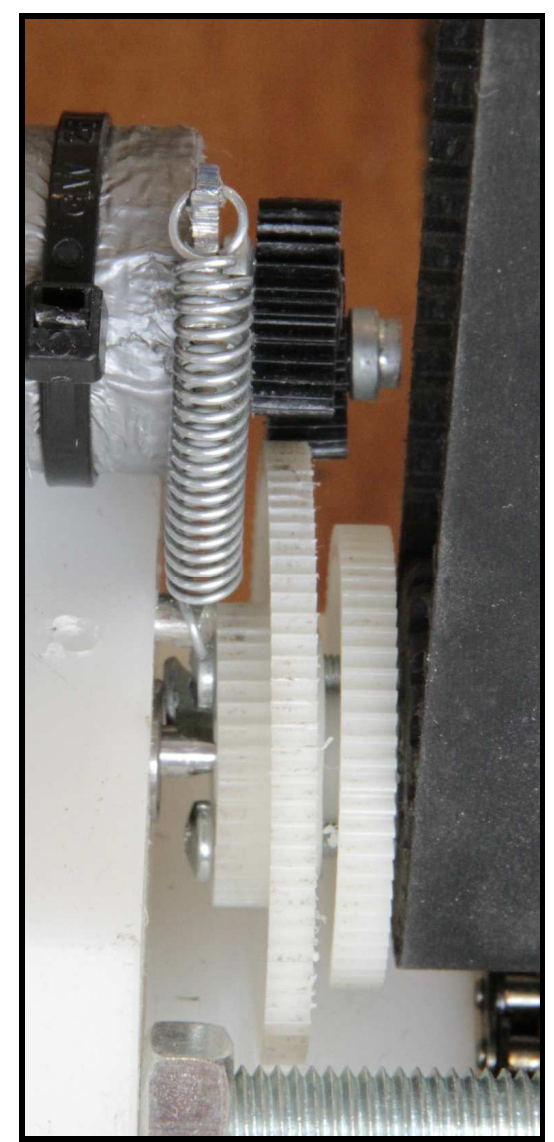

(c) Four spur gears of the timing belt.

Figure 35. Gears installed in ASRS model.

\subsubsection{Bearings}

Eight roller bearings with internal diamter of $4 \mathrm{~mm}$ were used in the ASRS model, Fig. 36. Four of them were used to support the chain (Sec. 3.2.1, Fig. 33) in the $x$-axis (first directon). They rest in the two side parts of the rigid base (Sec. 3.1.1, Fig. 3). The other four bearings support the timing belt (Sec. 3.2.2, Fig. 34) in the $y$-axis (second direction). They rest in the four guide bases ( $\mathrm{Sec}$. 3.1.3, Fig. 7).

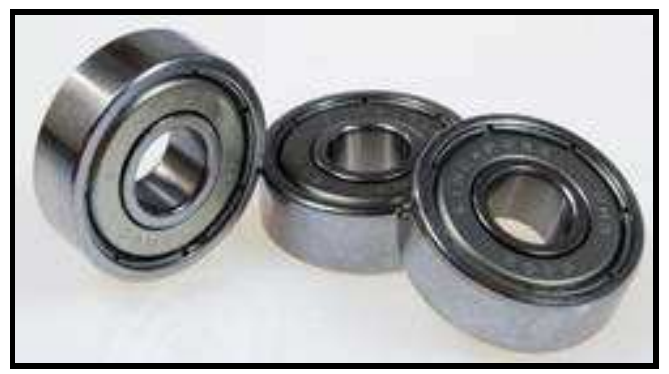

Figure 36. Bearings with 4 mm-internal diameter.

\subsubsection{Coupling}

A rigid coupling, Fig. 37, was used to connect an electrical motor to the chain gear (Sec. 3.2.3, Fig. 35a) that drives the chain (Sec. 3.2.1, Fig. 33) in the $x$-axis (first direction). The connection goes through one of the parts of the rigid base (Sec. 3.1.1, Fig. 3). 

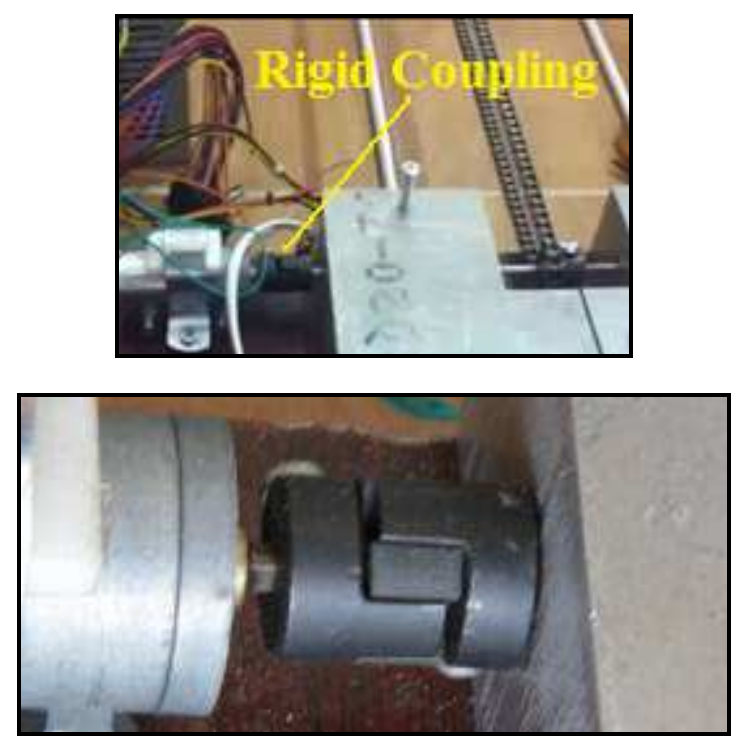

Figure 37. Rigid coupling installed in ASRS model.

\subsubsection{Spring}

A spring, Fig. 38, was used to ensure the engagement of the gears of the gear train that transfers motion from an electrical motor to the timing pulley (Sec. 3.1.14, Fig. 31). The timing pulley drives the ASRS in the $y$-axis (second direction).

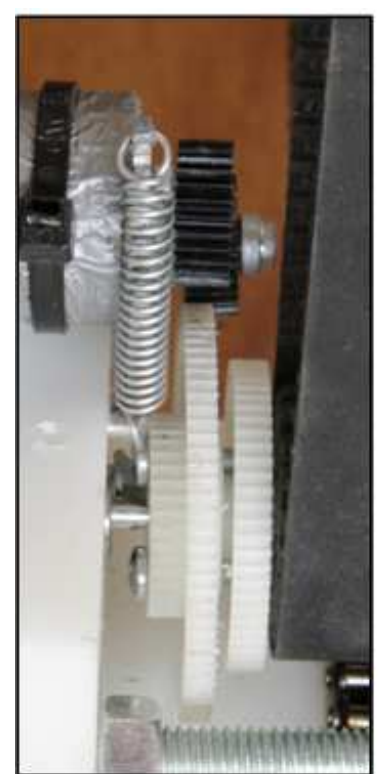

(a) Overall view.

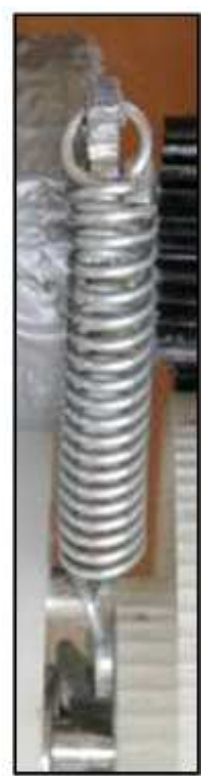

(b) Detailed view.
Figure 38. Spring installed in ASRS model.

\subsection{Cupboards (Pallets)}

\subsubsection{Description}

Cupboard was design to simulate the shelves (pallets) that hold the stock pieces, Fig. 39. It was fabricated of aluminum rods and plastic connections. Inventor software was used to carry out the design process. Two similar cupboards were used to simulate a working track of $A S R S$ between them.

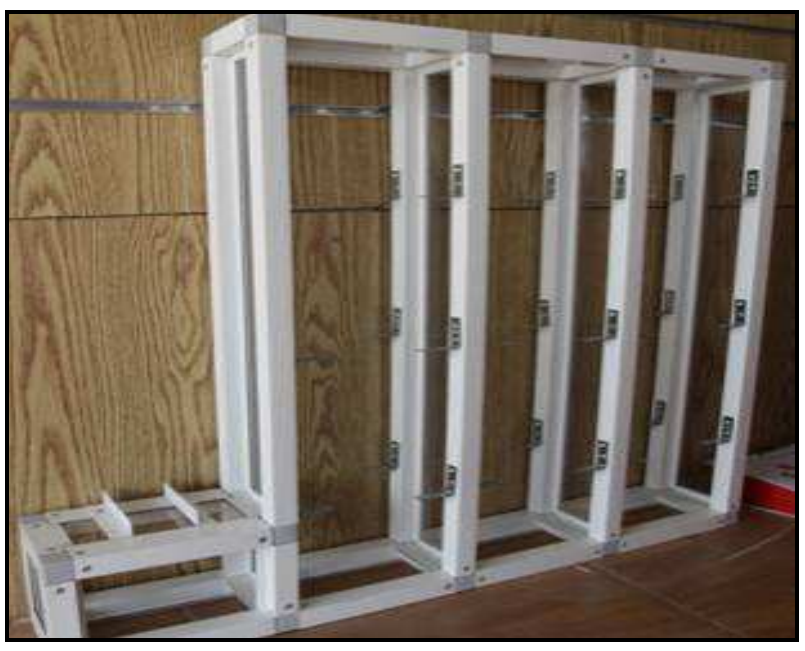

Figure 39. An overall view of the cupboard.

\subsubsection{Components of Cupboard}

The cupboard may be divided into two types of components as follows, Fig. 40:

(i) Pick-and-deposit station: It is where loads are transferred into and out of the $A S R S$. It is generally located at the end of the aisles for access the external handling system that brings loads to the $A S R S$ and takes loads away.

(ii) Compartments: They are the unit-load containers of the stored material.

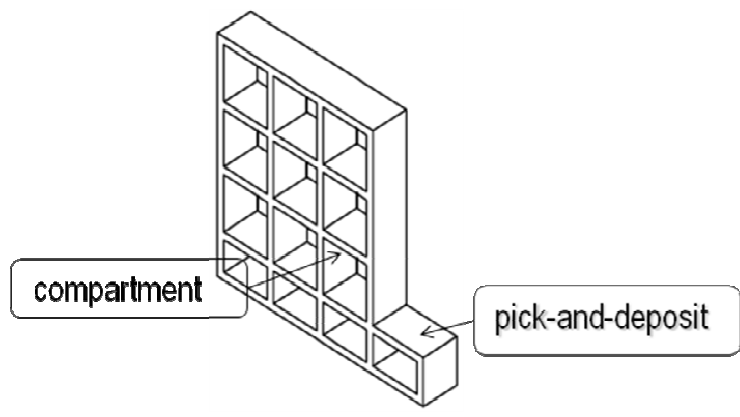

(a) Isometric

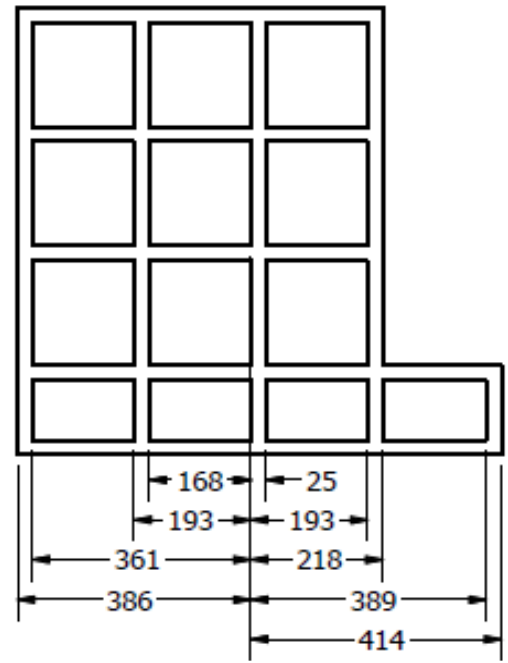

(b) Elevation 


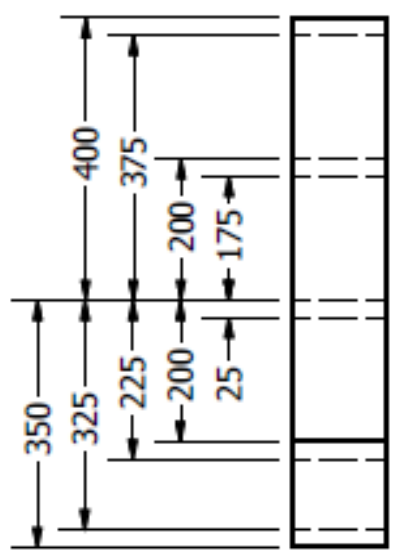

(c) Side view

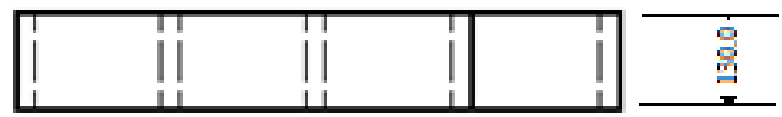

(d) Plan

Figure 40. Mechanical drawings of one of the two cupboards.

\subsubsection{Cupboard Fabrication}

The cupboard was fabricated from ready-made parts that are listed in table 3.

Table 3. Ready-made parts.

\begin{tabular}{lll}
\hline No. & Component & Material \\
\hline 1 & Sheet & Plastic \\
2 & Joint & Plastic \\
3 & Column & Aluminium \\
4 & Nail & Steel \\
\hline
\end{tabular}

\section{Electrical and Electronic Elements}

\subsection{Electrical Motors}

In the present project, there are two types of motors. The first type is the $D C$ motors and the second is the servomotors.

\subsubsection{Motors}

$D C$ motor is an electric motor that runs on direct current (DC) electricity. Today, $D C$ motors are still found in applications as small as toys and disk drives, or in large sizes to operate steel rolling mills and paper machines. Modern $D C$ motors are nearly always operated in conjunction with power electronic devices [27].

Two suitable $D C$ motors were used in the present project. The first $D C$ motor was used to drive the $A S R S$ components in the $x$-axis (first direction), Fig. 41a. The motor is connected to the driving chain gear (Sec. 3.2.3, Fig. 35a) through a rigid coupling ( $\mathrm{Sec}$. 3.2.5, Fig. 37). The second $D C$ motor was used to drive the $A S R S$ components in the $y$-axis (second direction), Fig. 41b. The motor is connected to the timing pulley (Sec. 3.1.14, Fig. 31) through a gear train (Sec. 3.2.3, Fig. 35c).

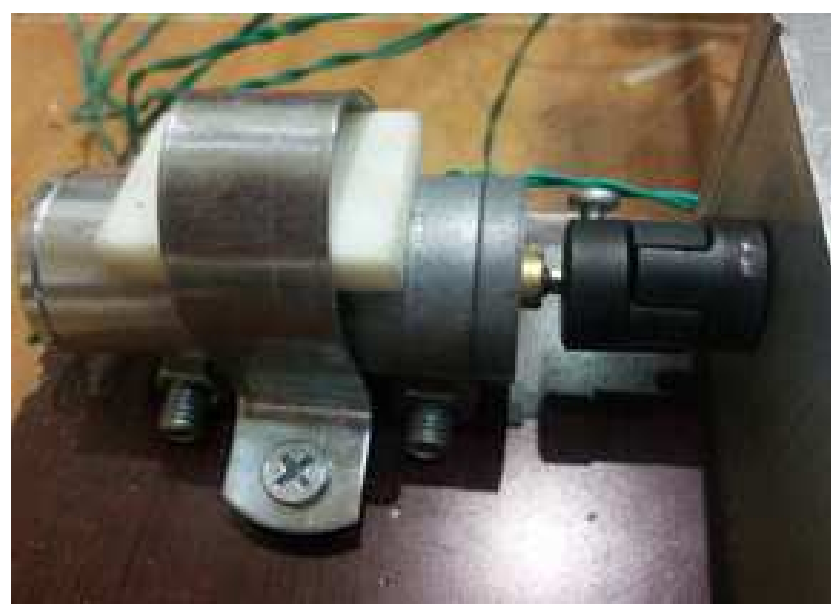

(a) DC Motor for driving in the $x$-axis.

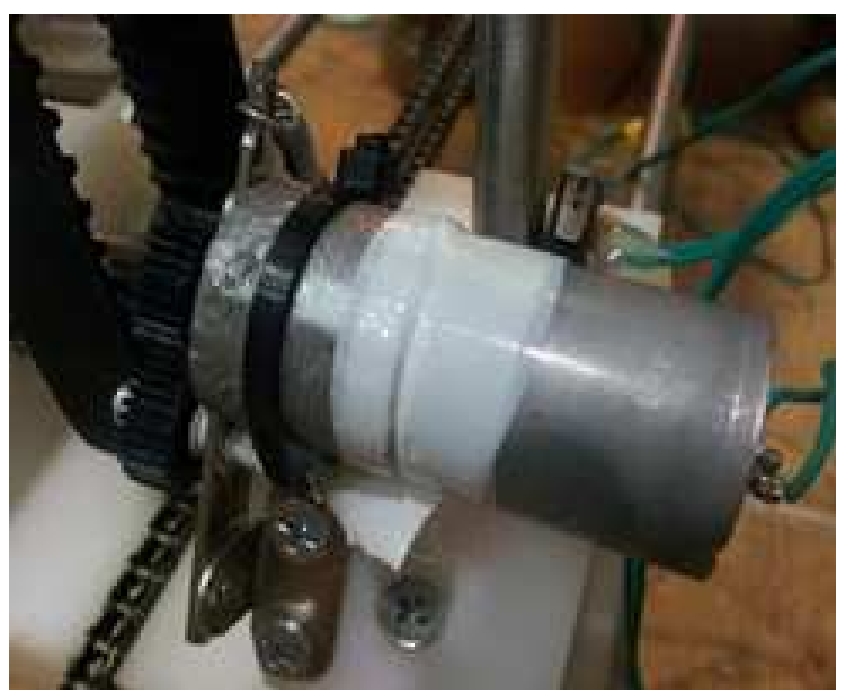

(b) $D C$ Motor for driving in the $y$-axis.

Figure 41. DC motors installed in ASRS model.

\subsubsection{Servomotors}

A servomotor is a motor which forms part of a servomechanism. The servomotor is paired with some type of encoder to provide position/speed feedback. This feedback loop is used to provide precise control of the mechanical degree of freedom driven by the motor. Servomotors have a range of $0^{\circ}-180^{\circ}$. For the serious designer of heavy duty and speed orientated equipment, servos offer the best solution [28].

In the present project two servomotors were used, Fig. 42. A servomotor was used to drive the ASRS components in the $z$-axis (third direction), Fig. 43 (black motor). The servomotor rests on the H-holder (Sec. 3.1.11, Fig. 23). Another servomotor, Fig. 42 (orange motor), controls the movement of the fork plate (Sec. 3.1.8, Fig. 17) and the fork arms (Sec. 3.1.9, Fig. 19) in a complete $180^{\circ}$ as can be seen in Fig. 44. 


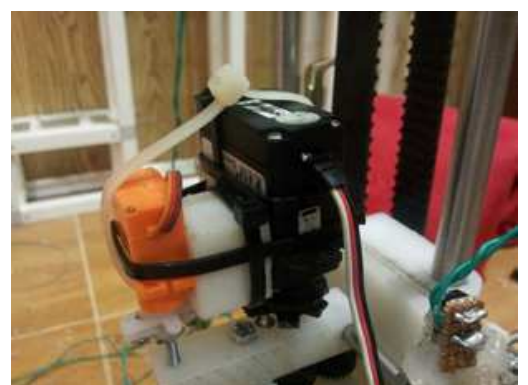

Figure 42. Servomotors installed in ASRS model for motion in z-axis (third direction).
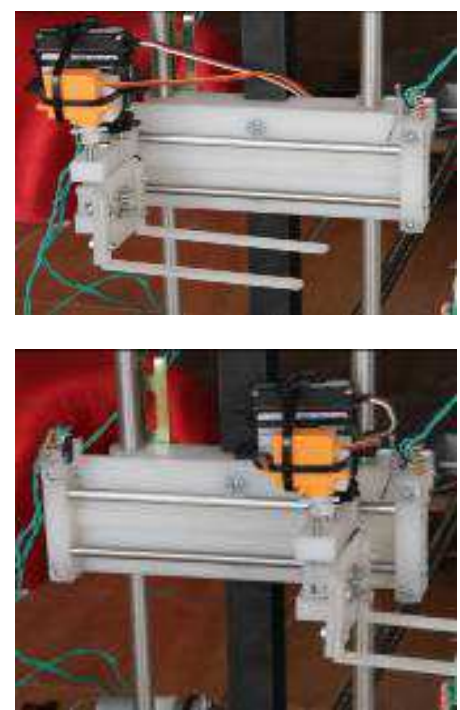

Figure 43. Forks moves in z-direction, right and left.
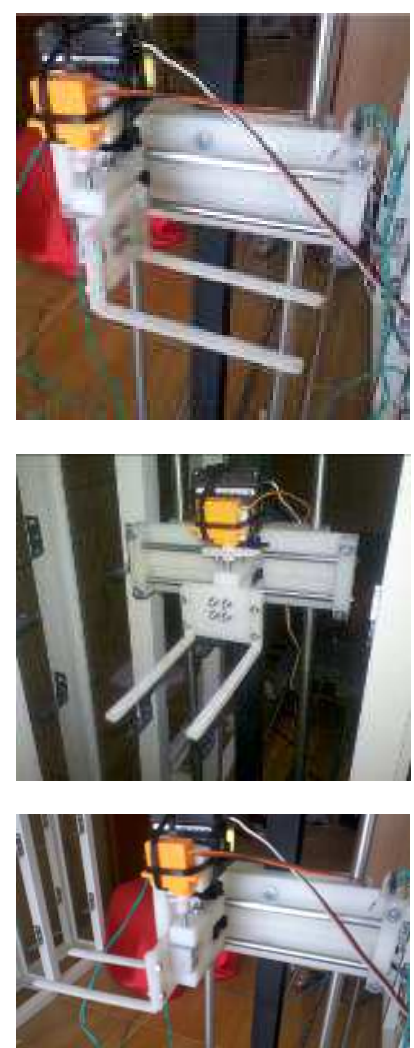

Figure 44. Forks turn from $0^{\circ}$ to $180^{\circ}$.

\subsection{Sensors}

In the present project, two types of sensors were used. A Light Dependent Resistor $(L D R)$ sensor was used to detect the pointing light. The other one is micro-switch sensor for cutting the circuit at the end of guide rod.

\subsubsection{Light Dependent Resistor (LDR)}

Light Dependent Resistor ( $L D R)$, Fig. 45, is also known as the general purpose photoconductive cell. It is a type of semiconductor and its conductivity changes with proportional change in the intensity of light. A photo resistor or light dependent resistor $(L D R)$ is a resistor whose resistance decreases with increasing incident light intensity; in other words, it exhibits photoconductivity. $L D R \mathrm{~s}$ are very useful especially in light/dark sensor circuits [30].

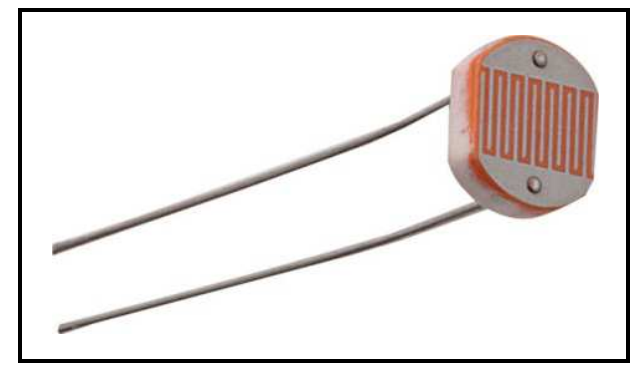

(a) Closer view.

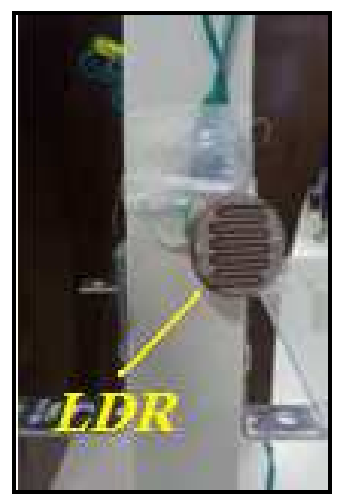

(b) $L D R$ installed in $A S R S$.

Figure 45. Light dependent resistor (LDR) [29].

A number of $6 L D R s$ were used in the present project. A beam of red light is emitted from the ASRS upper carriage. The carriage stops at the appropriate location when the light beam hits the corresponding $L D R$.

Figure 46 explains how the $L D R$ is utilized in the present project. At the beginning, the upper carriage stops at the "Pick-and-deposit station" when the light beam hits the corresponding $L D R$, Fig. 46a. Then, the carriage moves horizontally between the two cupboards until it reaches the following corresponding $L D R$ which is fixed on a column next to the target compartment, Fig. 46b. At that position, the carriage moves vertically looking for another $L D R$ at a point next to the target compartment, Fig. 46c. At that point, the carriage stops and the fork plate moves horizontally to deliver the load in the target compartment, Fig. 46d. 


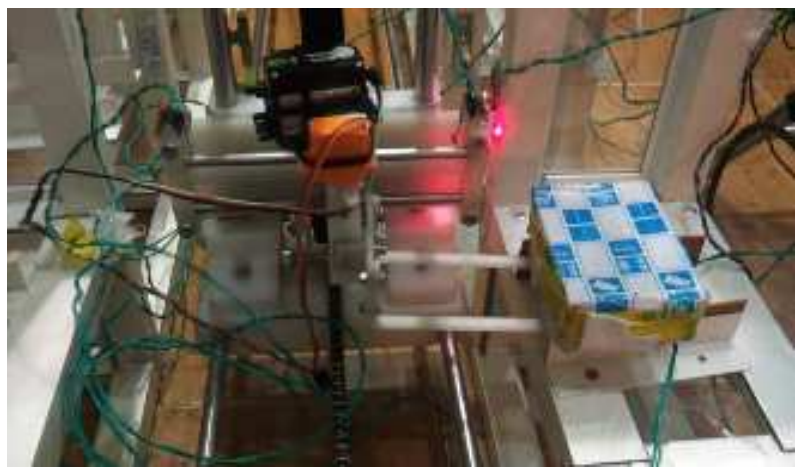

(a) $L D R$ at "Pick-and-deposit station".

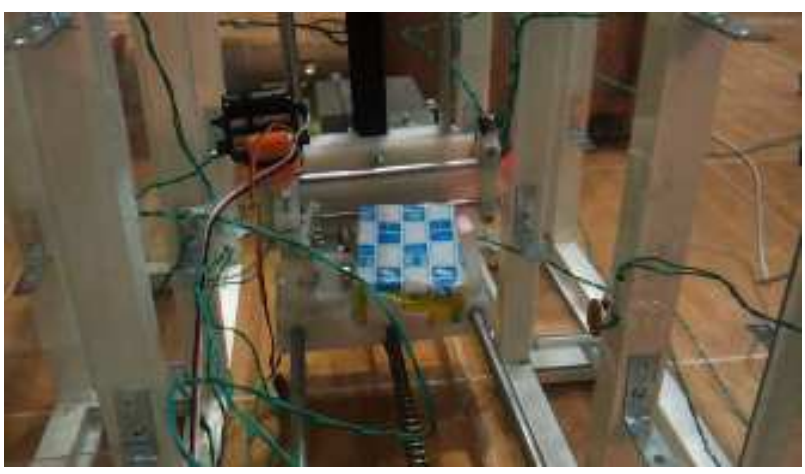

(b) $L D R$ at a column next to the target compartment.

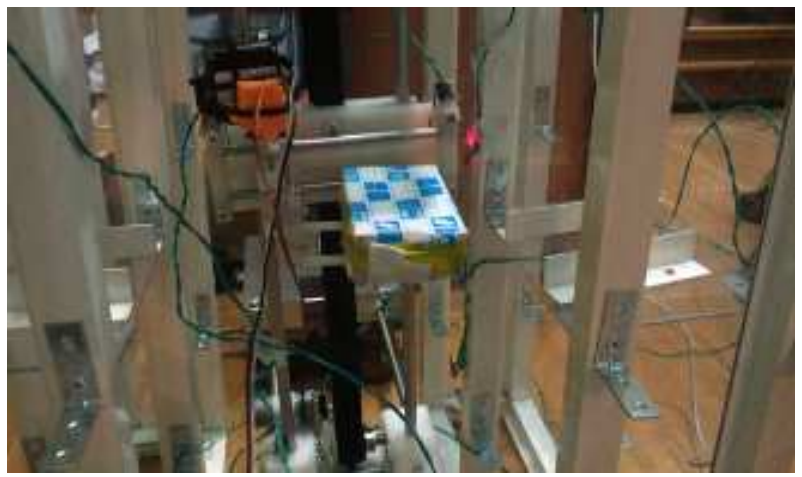

(c) $L D R$ at a point next to the target compartment.

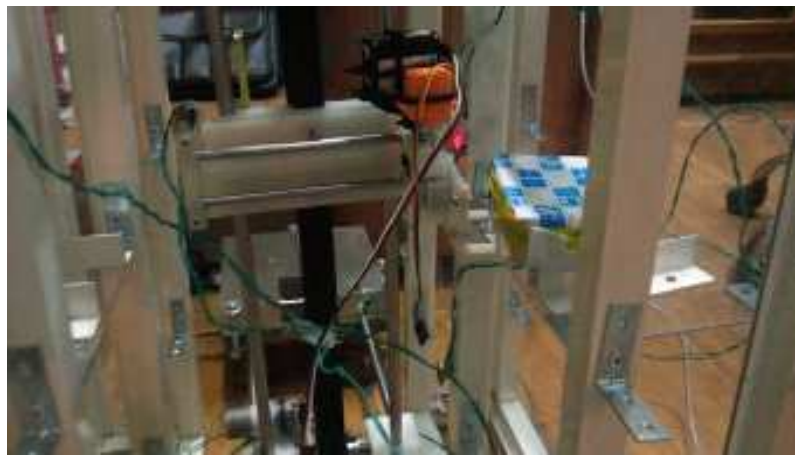

(d) Carriage unloading at the target compartment.

Figure 46. Steps of operation of SARS using LDRs.

\subsubsection{Micro-Switch}

It is also called miniature snap-action switch, Fig. 47. It is an electric switch that is actuated by very little physical force, through the use of a tipping-point mechanism, sometimes called an "over-center" mechanism. Switching happens reliably at specific and repeatable positions of the actuator, which is not necessarily true of other mechanisms. They are very common due to their low cost and durability, greater than 1 million cycles and up to 10 million cycles for heavy duty models. This durability is a natural consequence of the design. The defining feature of micro switches is that a relatively small movement at the actuator button produces a relatively large movement at the electrical contacts, which occurs at high speed (regardless of the speed of actuation). Most successful designs also exhibit hysteresis, meaning that a small reversal of the actuator is insufficient to reverse the contacts; there must be a significant movement in the opposite direction. Both of these characteristics help to achieve a clean and reliable interruption to the switched circuit [32].

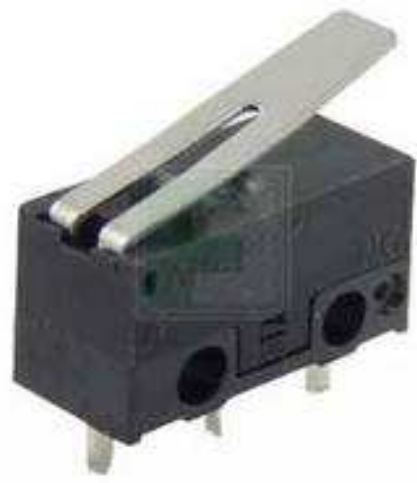

(a) Closer view.

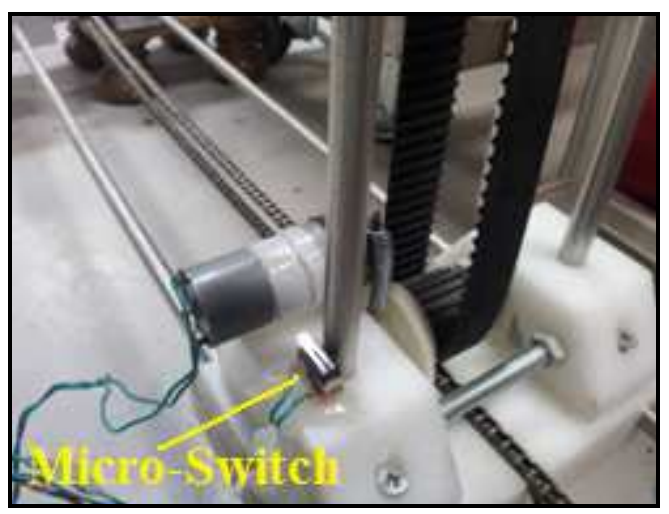

(b) Micro-switch installed in ASRS.

Figure 47. Micro-switch [31].

In the present project, 6 micro-switches were used to limit the movement of the upper and lower carriages in all the three directions ( $x$-, $y$-, and $z$-axis).

\subsection{Electronic Control Circuit}

An electronic circuit was designed and implemented based on experience of others [33]. The circuit consists of main components and other auxiliary components. The main components, including microcontroller, relays, and H-bridges, are illustrated in the following section. Auxiliary components include $I C \mathrm{~s}$, switches, fuses, wires, etc. 


\subsubsection{Main Components}

\section{(i) PIC Microcontroller}

The PIC microcontroller, Fig. 48, is a family of modified Harvard architecture microcontrollers made by Microchip Technology, derived from the PIC1650 originally developed by General Instrument's Microelectronics Division. The name PIC initially referred to "Peripheral Interface Controller". PICs are popular with both industrial developers and hobbyists alike due to their low cost, wide availability, large user base, extensive collection of application notes, availability of low cost or free development tools, and serial programming (and re-programming with flash memory) capability [35].

In the present circuit, the microcontroller was used as the main controller for the $S A R S$ machine. It receives the input from sensors and sends the output to the motors depending on the input signals from the sensors.

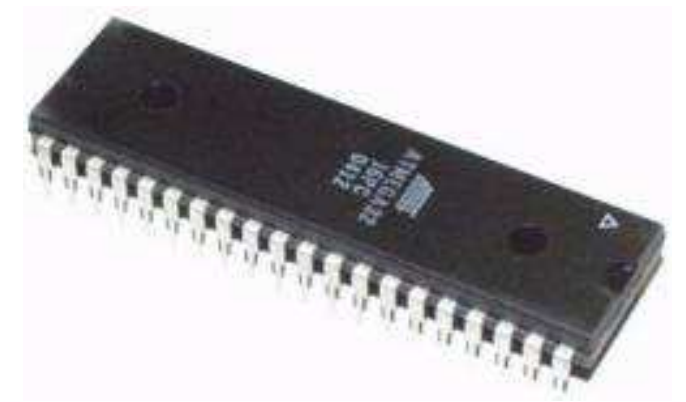

Figure 48. PIC Microcontroller [34].

\section{(ii) Relay}

A relay is an electrically operated switch. Many relays use an electromagnet to operate a switching mechanism mechanically, but other operating principles are also used, Fig. 49. Relays are used where it is necessary to control a circuit by a low-power signal (with complete electrical isolation between control and controlled circuits), or where several circuits must be controlled by one signal [37].

In the present circuit, a group of six similar relays were used, Fig. 49.

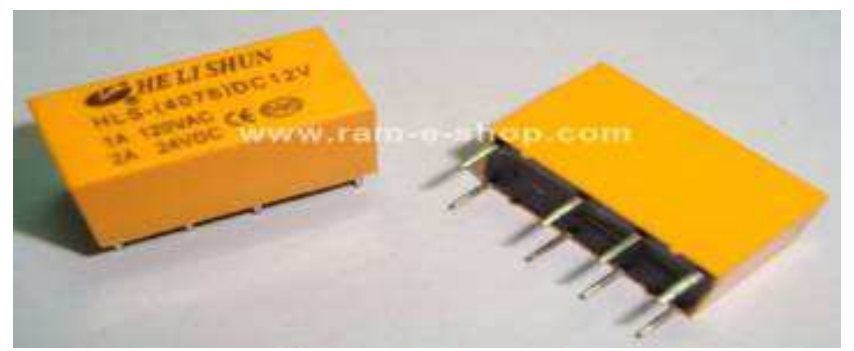

Figure 49. Relay [36].

\section{(iii) H-bridge}

An H-bridge, Fig. 50, is an electronic circuit that enables a voltage to be applied across a load in either direction. These circuits are often used in robotics and other applications to allow $D C$ motors to run forwards and backwards. H-bridges are available as integrated circuits, or can be built from discrete components [39].

In the present project, $\mathrm{H}$-bridges were used to switch the rotational direction of the motors. Thus, moves the ASRS carriages in either direction.

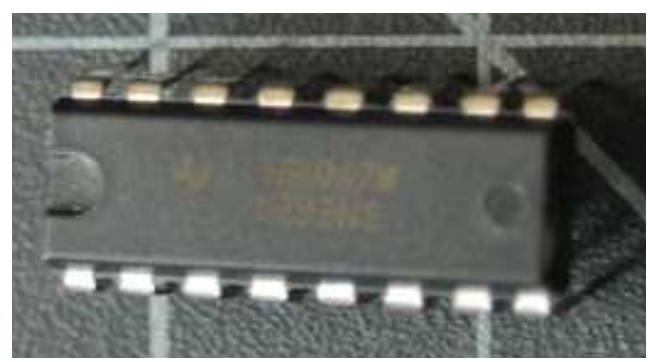

Figure 50. H-bridge [38].

\subsubsection{Programming Language}

Assembly language is a low-level programming language for computers, microprocessors, microcontrollers, and other integrated circuits. It implements a symbolic representation of the binary machine codes and other constants needed to program a given $C P U$ architecture. An assembly language is thus specific to certain physical (or virtual) computer architecture. This is in contrast to most high-level programming languages, which, ideally, are portable. A utility program called an assembler is used to translate assembly language statements into the target computer's machine code. The assembler performs a more or less isomorphic translation (one-to-one mapping) from mnemonic statements into machine instructions and data. This is in contrast with high-level languages, in which a single statement generally results in many machine instructions. Many sophisticated assemblers offer additional mechanisms to facilitate program development, control the assembly process, and aid debugging. In particular, most modern assemblers include a macro facility, and are called macro assemblers [40].

In the present project, the assembly language was used to program the microcontroller (Sec. 4.3.1.1, Fig. 48).

\subsubsection{Power Supply}

A power supply, Fig. 51, was used for electrical supply of the circuit. The input to the power supply is $A C 220 \mathrm{~V}$. The output of the power supply is $D C$ that ranges from 3 to $12 \mathrm{~V}$. This output is utilized by the different components of the circuit and the four motors.

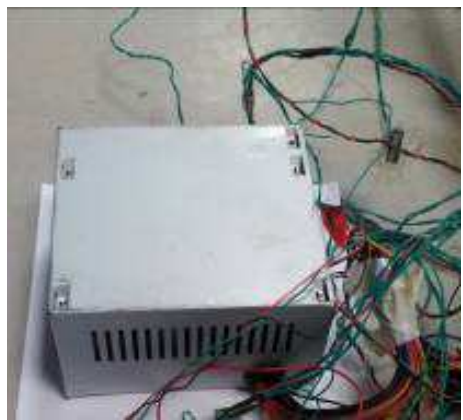

Figure 51. Power supply. 


\section{Actual Operation of $A S R S$}

\subsection{Test Case}

The present control circuit was implemented in conjunction with the $A S R S$ model to ensure that the design, manufacturing, programming were correct. Figure 52 shows the control circuit in operation. The objective is to move the load from the "Pick-and-deposit station" to the target compartment. To ensure that the ASRS model operates correctly, the control circuit was programmed to move the load (marked in "Blue") to a certain compartment, on one of the two cupboards, that is marked in "Red" as shown in Fig. 53.

When the microcontroller, which is connected to the sensors and push-button switches, receives the operation order, it sends an appropriate signal to the corresponding relay that in turn controls an $\mathrm{H}$-bridge. Thus, the H-bridge controls the related motor to rotate either in clockwise or anti-clockwise directions. The operation continues sequentially as programmed until the packer delivers the unit-load into place.

The test was carried out very successfully as was shown in step-by-step sequence in Sec. 4.2.1 and illustrated in Fig. 46.

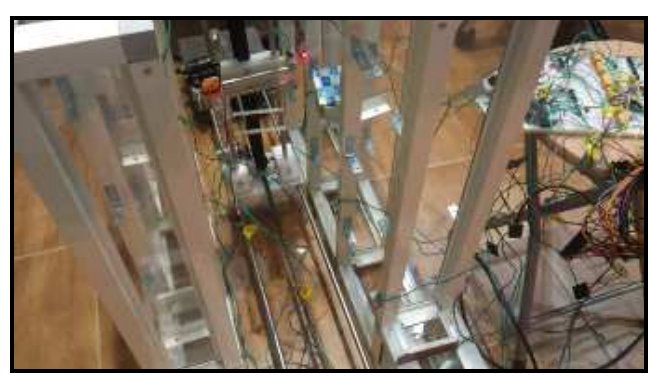

(a) Overall View.

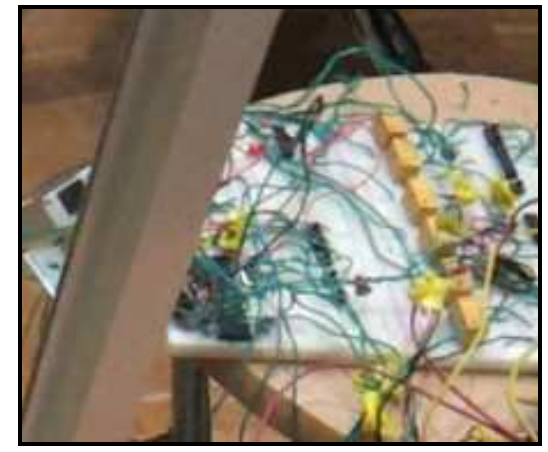

(b) Closer view.

Figure 52. Electronic control circuit of ASRS model.

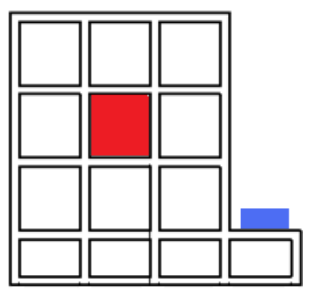

Figure 53. Locations of load (blue) and target compartment (red).

\subsection{Faced Problems}

During the design and manufacturing phases of this project, the students faced some practical problems that may be listed as follows:

1. Deciding the most suitable design as there is a big variety of $A S R S$.

2. Material selection as there is somehow limitations in the local market.

3. Shortage in workshops that provide accurate machine tooling.

4. Standard gears with small sizes are not available in the local market. They had to be specifically manufactured.

5. Fixing the motors on $A S R S$ model due to their small sizes.

6. Arranging the big number of connecting and control wires.

\section{Proposed Firefighting Utilizing $A S R S$}

\subsection{Firefighting in Warehouses}

The traditional method for firefighting (suppression) in $A S R S$ warehouses is the sprinklers. Sprinkler systems are widely known and they have the advantage of being relatively easy to supply and construct in site. However, using them in $A S R S$ warehouses have some disadvantages [41-43]: (i) Huge amount of water is needed to supply the sprinkler systems. (ii) Water destroys the stock if it is consisted of cartooned items. (iii) ASRS warehouses are usually so dense that firefighters' accessibility is noticeably low. (iv) Dense (high-storage capacity) warehouses prevent the sprinkler water from reaching the lower levels of pallets.

Thus, an alternative technique may be used instead of sprinklers or besides them. Based on the practical experience of this project, a proposed method is explained in the following section.

\subsection{Proposed Firefighting Technique}

The proposed technique depends on using the ASRS to deliver a package (unit-load) of dry chemical powder. Thus, immediate fire-extinction is expected by chemical reaction in an instant. Usually, dry powder is used in situations where water would have a negative impact on fires or substances stored near a fire source. It is preferable that the powder is suitable for a wide range of fire classes (A, B, C, D) [44-46].

The proposed technique is more suitable to the case when the warehouse contains valuable/precious stock pieces. Examples of such warehouses are $A S R S$ university libraries [47-50], libraries of motion pictures and television programs [51], etc.

The idea of the technique can be summarized in the following points:

1. Suitable set of fire detectors [52-54] are used such that a detector is placed in each compartment of the warehouse.

2. Dry powder packages are prepared in certain section of 
the warehouse near the "Pick-and-deposit station".

3. The size of the powder packages fits the compartment size.

4. The material of the powder package is to be chosen to tear out immediately when exposed to fire heat/flame.

5. All the fire detectors are connected to the electronic control circuit (Sec. 4.3).

6. When a detector of certain compartment sends a fire signal to the electronic circuit, a fire alarm operates. Thus, operators put one of the powder packages in "Pick-and-deposit station".

7. Then, the microcontroller gives the pre-programmed orders to the ASRS to carry the powder package from the "Pick-and-deposit station" to the target compartment (on-fire compartment).

8. This procedure may continue several times till the fire is completely extinct.

Unfortunately, this technique was not tested experimentally in this project due to some practical difficulties. However, it is planned to be implemented as a further extension of the present project.

\section{Conclusions}

Based on the above illustrations and test observations, the following points can be stated:

1. The present ASRS model operated successfully and performed exactly the target task.

2. The students gained a really big experience in design, material selection, and manufacturing of such complicated mechanical system.

3. Although the electronic circuit was simple, it was implemented successfully.

4. There are some practical problems that were faced by the students. These problems should be put into consideration when considering similar types of projects.

5. The strategy of using the $A S R S$ packer for firefighting is an interesting trend of thinking out of the box.

6. Economic feasibility study may be needed when considering the manufacturing of a full-scale prototype.

7. Although, the proposed technique of firefighting was not tested experimentally in this project due to some practical difficulties, it seems very promising.

\section{Acknowledgement}

The author would like to acknowledge Engs. M. A. Alhazmi, A. A. Imam, M. M. Olaqi, A. Y. Bawzer, and W. M. Sindi as being members of the team of the B.Sc. Graduation project of the present work under the author's supervision.

\section{Nomenclature}

$A C \quad$ Alternating Current

ASRS Automated Storage and Retrieval System $(A S / R S)$
$C P U \quad$ Central Processing Unit
$D C \quad$ Direct Current
IC Integrated circuit
LDR Light Dependent Resistor
$S R \quad$ Storage and Retrieval
PIC Peripheral Interface Controller
PTFE Polytetrafluoroethylene (Teflon)

\section{References}

[1] J. Rhee, C. Oyamot, D. Parent, L. Speer, A. Basu, and L. Gerston, "A Case Study of a Co-Instructed Multidisciplinary Senior Capstone Project in Sustainability", Advances in Engineering Education, Vol. 4, No. 2, 2014.

[2] https://eeic.osu.edu/multidisciplinary-engineering-capstonedesign

[3] P. K. Imbrie, K. Haghighi, P. Wankat, and W. Oakes, "Creating a Model Multidisciplinary Engineering Program", Proceedings of the 2005 ASEE/AaeE 4th Global Colloquium, 2005.

[4] K. Wolff, and K. Luckett, "Integrating Multidisciplinary Engineering Knowledge", Teaching in Higher Education, Vol. 18, No. 1, pp. 78-92, 2013.

[5] K. Craig, and P. Voglewede, "Multidisciplinary Engineering Systems Graduate Education: Master of Engineering in Mechatronics", Transforming Engineering Education: Creating Interdisciplinary Skills for Complex Global Environments, 2010 IEEE , Dublin, 6-9 April 2010, pp. 1-14.

[6] C. Telenko, B. Camburn, and K. Wood, "Designettes: New Approaches to Multidisciplinary Engineering Design Education", Proceedings of the ASME 2014 International Design Engineering Technical Conferences \& Computers and Information in Engineering Conference (IDETC/CIE 2014), Buffalo, New York, USA, August 17-20, 2014, DETC201435137.

[7] M. Parten, D. Vines, J. Jones, and A. Ertas, "Program for Multidisciplinary Engineering Projects", Proceedings of Frontiers in Education Conference, 1996, FIE '96. 26th Annual Conference, Salt Lake City, UT, 6-9 Nov., 1996, Vol. 3, pp. 1309-1312.

[8] F. Sahin, and W. Walter, "Multidisciplinary Microrobotics Teaching Activities in Engineering Education", Proceedings of the 2003 American Society for Engineering Education Annual Conference \& Exposition 2003.

[9] J. L. Cezeaux, E. W. Haffner, and T. Keyser, "The Evolution of a Collaborative Multidisciplinary Engineering Design Experience", Proceedings of The International Conference on Engineering \& Technology (The 2008 IAJC-IJME International Conference, ISBN 978-1-60643-379-9), Music City Sheraton, Nashville, TN, USA, November 17-19, 2008, Paper \#094, ENG 107.

[10] P. J. Robbie, I. Baker, W. Lotko, J. P. Collier, "A Multidisciplinary Approach to Introductory Engineering Design", 38th ASEE/IEEE Frontiers in Education Conference, Saratoga Springs, NY, USA, October 22-25, 2008.

[11] http://racksandrollers.com/automated-storage-retrivalsystems-warehouse 
[12] K. J. Roodbergen, and I. F. A. Vis, "A Survey of Literature on Automated Storage and Retrieval Systems", European Journal of Operational Research, Vol. 194, No. 2, pp. 343-362, 16 April 2009, DOI: 10.1016/j.ejor.2008.01.038.

[13] M. Dotoli, M. P. Fanti, and G. Iacobellis, "Comparing Deadlock Detection and Avoidance Policies in Automated Storage and Retrieval Systems", Systems, Man and Cybernetics, 2004 IEEE International Conference, 10-13 Oct. 2004, pp. 1607-1612, Vol. 2, DOI: 10.1109/ICSMC.2004.1399861

[14] Y.-H. Hu, S. Y. Huang, C. Chen, W.-J. Hsu, A. C. Toh, C. K. Loh, and T. Song, "Travel Time Analysis of a New Automated storage and Retrieval System", Computers \& Operations Research, Vol. 32, pp. 1515-1544, 2005.

[15] M. Dotoli, and M. P. Fanti, "Deadlock Detection and Avoidance Strategies for Automated Storage and Retrieval Systems", Systems, Man, and Cybernetics, Part C: Applications and Reviews, IEEE Transactions, Vol. 37, No. 4, pp. 541-552, July 2007, DOI: 10.1109/TSMCC.2007.897690

[16] C. Kator, "Automated Storage and Retrieval System (AS/RS) Basics", Modern Materials Handling, August 1, 2007.

[17] G. Moon, and G.-P. Kim, "Effects of Relocation to AS/RS Storage Location Policy with Production Quantity Variation", Computers \& Industrial Engineering, Vol. 40, pp. 1-13, 2001.

[18] Automated Storage \& Retrieval System: Material Handling Machines, Application Bulletin, No. 0108AB9707, Square D Company, 1997.

[19] http://www.mhia.org/industrygroups/as-rs

[20] http://www.atlastechnologies.com/pdfs/ASRS.pdf

[21] http://www.westfaliausa.com/products/ASRS/documents/ASR S_Innovations_WhitePaper_2009-Web.pdf

[22] http://library.csun.edu/About/ASRS

[23] http://www.vrhandling.ch/En/LinkClick.aspx?fileticket=aVBP t8g0kGA\%3d\&tabid $=2839 \&$ language $=$ de $-\mathrm{CH}$

[24] http://www.directindustry.com/prod/lodige/storage-systems19118-1161081.html

[25] A. H. B. Hadzir, Development of Automated Storage and Retrieval System (AS/RS) Prototype", B.Sc. Mechanical Engineering, Faculty of Mechanical Engineering, Universiti Malaysia Pahang, December 2010: http://umpir.ump.edu.my/1751/1/Abdul_Halim_Hadzir_(CD _5008_).pdf

[26] http://www.ignou.ac.in/upload/Unit4-55.pdf

[27] S. Shrivastava, J. Rawat, and A. Agrawal, "Controlling DC Motor Using Microcontroller (PIC16F72) with PWM", International Journal of Engineering Research, Vol. 1, No. 2, pp. 45-47, 1 Dec. 2012.

[28] http://unirobotics.co.za/store/22-servo-motors-controllers

[29] http://www.raspberrypi-spy.co.uk/2012/08/reading-analoguesensors-with-one-gpio-pin/

[30] D.V.P. Latha, "Simulation of PLC based Smart Street Lighting Control using LDR", International Journal of Latest Trends in Engineering and Technology (IJLTET), Vol. 2, No. 4, pp. 113121, July 2013.
[31] http://www.futureelectronics.com/en/technologies/electromec hanical/switches/snap-acting/Pages/6907612DG13B1LA.aspx

[32] http://www.langir.com/htm/cm-micro-switch.htm

[33] M. M. A. Zaki, H. M. Monier, and R. F. Rageh, "Automatic Storage Machine", B. Sc. Graduation Project, Supervisor: M. Abd-Elqawy, Computer \& Systems Dept., Faculty of Eng., Zagazig Univ., Egypt, 2011.

[34] http://www.societyofrobots.com/microcontroller_tutorial.shtml

[35] http://bitstream24.com/embedded-c-programming-with-themicrochip-pic-microcontroller

[36] http://ram-e-

shop.com/oscmax/catalog/index.php?cPath=29\&osCsid=3319 a177028ed9b332352a465b26dbcf

[37] https://www.princeton.edu/ achaney/tmve/wiki100k/docs/Rel ay.html

[38] http://www.electronics-lab.com/blog/?tag=h-bridge

[39] http://www.ez-robot.com/Tutorials/Hardware.aspx?id=25

[40] http://www.princeton.edu/ achaney/tmve/wiki100k/docs/Asse mbly_language.html

[41] D. T. Gottuk, and J. Dinaburg, Fire Detection in Warehouse Facilities, Springer Science \& Business Media, 2012. ISBN: 978-1-4614-8115-7. DOI: 10.1007/978-1-4614-8115-7

[42] S. Martorano, "Sprinkler Protection for High Bay and Automated Storage in Warehouse-Type Storage Facilities", Technical Article, February, 2010: http://www.vikinggroupinc.com/techarticles/Sprinkler\%20Pro tection $\% 20$ for $\% 20 \mathrm{High} \% 20 \mathrm{Bay} \% 20$ and $\% 20$ Automated $\% 20 \mathrm{~S}$ torage $\% 20 \mathrm{in} \% 20$ Warehouse $\% 20$ Type $\% 20$ Storage $\% 20$ Faciliti es.pdf

[43] http://www.klausbruckner.com/blog/global-research-updatehigh-challenge-storage-protection/

[44] http://www.ruehl-ag.de/en/fire-extinguishingagents/products/fire-fighting-dry-chemical-powders.html

[45] http://www.protech-i.jp/fire/drypowder_eg.html

[46] http://www.rosenbauer.com/en/rosenbauerworld/products/industrial-vehicles/dry-powder-firetrucks.html?tx_rosenbauersprachmenu_pi2 $\% 5$ Bcountry $\% 5 \mathrm{D}=$ $253 \&$ tx rosenbauersprachmenu pi $\% \overline{5 B a c t i o n} \% 5 \mathrm{D}=$ showCo untry\&tx_rosenbauersprachmenu_pi $2 \% 5 \mathrm{Bcontroller} \% 5 \mathrm{D}=\mathrm{La}$ nd\&cHash $=8 d f 2 d d 36 d 587602$ f9facdf3917bbda1 8

[47] Helen Heinrich, and Eric Willis ,"Automated storage and retrieval system: a time-tested innovation", Library Management, Vol. 35, No. 6/7, pp.444 - 453, 2014. DOI: http://dx.doi.org/10.1108/LM-09-2013-0086

[48] http://library.csun.edu/About/ASRS

[49] http://library.umkc.edu/newmnl/about-robot

[50] http://library.sonoma.edu/about/building/ars/

[51] http://www.elecompack.com/casestudies/asrsparamountcs.pdf

[52] "Selection and Location of Fire Detectors". http://www.fire.org.nz/Business-FireSafety/UnwantedAlarms/Documents/69efc74f885837062a01a e02b0e57a39.pdf 

and Retrieval System $(A S R S)$ for Firefighting in Warehouses

[53] Sierra monitor corporation, Flame Detector Selection Guide, Rev. A1-11/10, 2010. http://www.sierramonitor.com/docs/pdf/flame detector_selecti on.pdf
[54] L. Grosse, J. DeJong, and J. Murphy, "Risk Analysis of Residential Fire Detector Performance", August 1995. http://hrrc.arch.tamu.edu/media/cms page media/558/9501R.pdf 